\title{
Effect of high intensity interval training on body composition in women before and after menopause: a meta-analysis
}

\author{
Marine Dupuit $^{1}$ | Florie Maillard ${ }^{1}$ | Bruno Pereira ${ }^{2}$ (c) | Marcelo Luis Marquezi ${ }^{3}$ \\ Antonio Herbert Lancha Jr ${ }^{3} \quad$ Nathalie Boisseau ${ }^{1,4}$ (])
}

${ }^{1}$ Laboratory of Metabolic Adaptations to Exercise under Physiological and Pathological Conditions (AME2P), Université Clermont Auvergne, EA 3533, Clermont-Ferrand 63171, France

${ }^{2}$ Clermont-Ferrand University Hospital, Biostatistics Unit (DRCI), Clermont-Ferrand 63000, France

${ }^{3}$ Escola de Educação Física e Esporte, Universidade de São Paulo, Brazil

${ }^{4} \mathrm{CRNH}$ - Auvergne-Rhône-Alpes (CNRH-AURA), Clermont-Ferrand 63000, France

Correspondence

Nathalie Boisseau, Laboratoire des Adaptations Métaboliques à l'Exercice en conditions Physiologiques et Pathologiques (AME2P), BP 80026, F-63171, Aubière Cedex, France.

Email:nathalie.boisseau@uca.fr

Edited by: Jeremy Ward

Funding information

This research did not receive any specific grant from funding agencies in the public, commercial, or not-for-profit sectors.

\begin{abstract}
High-intensity interval training (HIIT) is a stimulating modality for reducing body weight and adipose tissue. The purpose of this meta-analysis was to assess the efficacy of HIIT in reducing weight, total fat mass (FM) and (intra)-abdominal FM in normalweight and overweight/obese women before and after menopause. A structured electronic search was performed to find all publications relevant to our review. Stratified analyses were made of hormonal status (pre- vs. postmenopausal state), weight, HIIT modalities (cycling vs. running), programme duration ( $<$ or $\geq 8$ weeks) and the methods used to measure body composition (dual-energy $\mathrm{X}$-ray absorptiometry vs. computed tomography, Magnetic Resonance Imaging and others). A total of 38 studies involving 959 subjects were included. Our meta-analysis showed that overall HIIT programmes significantly decrease weight, total and abdominal FM in women. Both normal weight and overweight/obese women lost total FM after HIIT protocols whereas HIIT was only effective in decreasing abdominal FM in women with excess adiposity. When pre- and postmenopausal women were considered separately, the effect of HIIT on weight, total and abdominal FM were only significant before menopause. Cycling HIIT seemed more effective than running, especially in postmenopausal women, and training interventions longer than 8 weeks comprising three sessions were more efficient. HIIT is a successful strategy to lose weight and FM in normal weight and overweight/obese women. However, further studies are still needed to draw meaningful conclusions about the real effectiveness of HIIT protocols in postmenopausal women.
\end{abstract}

KEYWORDS

abdominal fat mass, fat mass, high-intensity interval training, menopause, women

\section{1 | INTRODUCTION}

Numerous studies in women show an increased risk of obesity in midlife (Kapoor, Collazo-Clavell, \& Faubion, 2017; Lizcano \& Guzmán, 2014). At menopause, this risk increases and with it obesity-related disorders such as hypertension, hypercholesterolaemia and type 2 diabetes (Monteleone, Mascagni, Giannini, Genazzani, \& Simoncini,
2018). The greater occurrence of metabolic diseases is related to body composition changes, such as an increased amount of total body fat, a loss of lean body mass and changes in body fat mass (FM) distribution (Abildgaard et al., 2013). In premenopausal women, the total amount of abdominal fat (including visceral deposits) is lower and reduces the risk of metabolic syndrome (Palmer \& Clegg, 2015). However, after menopause, body fat distribution shifts to a male profile ('android type', 
also called central obesity) thereby increasing the risk of developing metabolic syndrome and several chronic diseases such as cardiovascular diseases (CVD) (Kapoor et al., 2017; Karvonen-Gutierrez \& Kim, 2016).

The management of weight and FM loss in premenopausal and postmenopausal women is a major public health concern (Dolin \& Kominiarek, 2018). To promote body weight and FM reductions, an energy imbalance is required (i.e. energy input $<$ energy output). Data from the literature show that short- and long-term programmes based on nutritional recommendations alone are less effective than those that also include regular physical activity (Hassan, Latif, \& Yacoub, 2012; Verheggen et al., 2016). Current international guidelines mostly recommend moderate-intensity continuous training (MICT) as the best strategy in both men and women to reduce body weight and FM, mainly because of the duration and intensity of the sessions, which promote fat mobilization and oxidation (Donnelly et al., 2009). However, without contesting its positive cardiovascular and metabolic effects, this training mode generally leads to little or no fat loss (Boutcher, 2011). High intensity interval raining (HIIT) - repeated bouts of high-intensity effort ranging between $\sim 80 \%$ and $100 \%$ peak heart rate followed by less intense recovery times (Maclnnis \& Gibala, 2017; Weston, Wisløff, \& Coombes, 2014) - has recently been proposed as a timeefficient modality to increase post-exercise lipid oxidation, which helps to reduce body weight and adipose tissue (Boutcher, 2011; Karstoft, Wallis, Pedersen, \& Solomon, 2016; Wewege, van den Berg, Ward, \& Keech, 2017) including (intra)-abdominal FM, the most dangerous one (Maillard et al., 2018).

Numerous publications and reviews are now available concerning HIIT-induced health benefits including body weight and FM losses (Maillard et al., 2018; Roy et al., 2018; Türk et al., 2017) but none of them focus specifically on women and none of them take into account the hormonal status of these women. Yet, it is well known that the oestrogen deficiency observed at menopause can alter metabolic adaptations to exercise (Isacco \& Boisseau, 2017). For these reasons, the beneficial effects on body composition induced by HIIT could be altered in postmenopausal women and hence lead to inappropriate recommendations.

The aim of this review was to establish from these literature data the efficacy of HIIT in reducing weight, total and (intra)-abdominal FM in women before and after menopause. The analysis was applied to normal-weight and overweight/obese women. To arrive at practical recommendations, particular attention was paid to the type of the HIIT (cycling vs. running), the duration of the programmes ( $<$ or $\geq 8$ weeks) and the methods used to measure body composition.

\section{2 | METHODS}

\subsection{Literature search strategy}

PubMed/MEDLINE, EMBASE, Google Scholar, Cochrane and Web of Science up to December 2019 were used to identify related studies. The keywords chosen were 'high intensity interval training' (HIIT),

\section{New Findings}

- What is the topic of this review?

A meta-analysis of the efficacy of high intensity interval training (HIIT) in reducing weight, total fat mass (FM) and (intra)-abdominal FM in normalweight and overweight/obese women before and after menopause.

\section{- What advances does it highlight?}

HIIT programmes in women significantly decrease body weight and total and abdominal FM. Their effects are more evident in pre- than in postmenopausal women. Cycling HIIT seems more effective than running, especially in postmenopausal women, and training interventions longer than 8 weeks comprising three sessions a week should be promoted.

'high-intensity intermittent exercise' (HIIE), 'aerobic interval exercise' (AIE) or 'aerobic interval training' (AIT), with and without 'women', 'girl', 'female' or 'body composition', 'body fat', 'fat mass'. A manual search of reference lists and citations was conducted to find potentially relevant studies. Publications in English and French were retained for analysis.

\subsection{Inclusion and non-inclusion criteria}

Inclusion criteria were (a) studies using HIIT protocols with running, cycling and elliptical modalities without restrictions to the duration of the protocol and the HIIT modality, and (b) adult women ( $\geq 18$ years old) with normal weight, overweight or obesity. Only adult women were analysed because training adaptations and substrate use differ with sex and age. Non-inclusion criteria were (a) studies including energy restrictions or specific diets, (b) studies using supramaximal interval training (SIT) protocols, and (c) studies including high-level athletes. However, when publications referred incorrectly to 'SIT' or 'Wingate' protocols' (i.e. when subjects performed with an intensity level below $100 \%$ of the peak heart rate), the data were included. Pre-/postmenopausal women were categorized as such when the distinction was clearly mentioned in the publications.

\subsection{Data extraction}

For each study, the first author and second author (M.D. and F.M.) separately extracted the data from all the publications with advice from N.B. on selection criteria. We summarized the following information.

- Protocol characteristics: exercise type (running vs. cycling), HIIT protocol, duration and frequency. 
FIGURE 1 Flow diagram of the systematic reviewing process

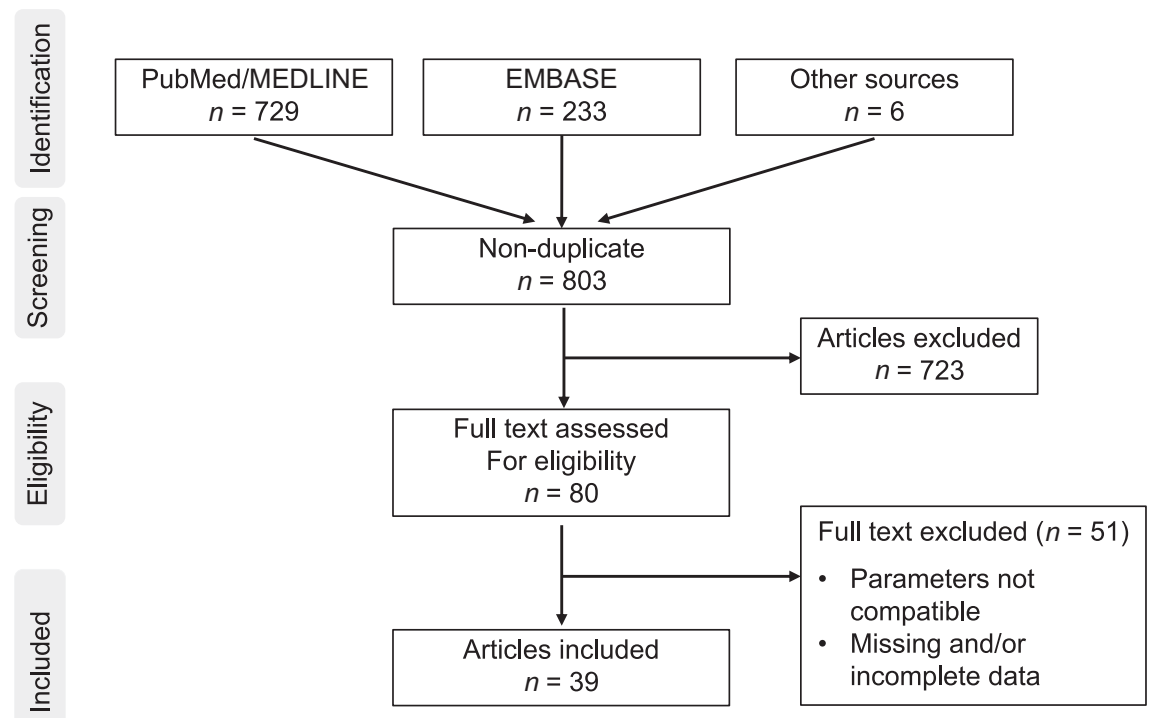

- Population characteristics: number of subjects, age, body mass index, body composition measurements, other information.

- Outcome measures: weight, total FM, abdominal FM and visceral FM.

Authors of the studies selected were contacted for missing values.

\subsection{Study quality}

Study quality was assessed by M.D. and F.M. using a checklist adapted from Downs \& Black (1998) and Keating, Johnson, Mielke, \& Coombes (2017). All the studies were retained irrespective of the score obtained. Items included 19 questions about hypotheses, outcomes, patient characteristics (on the basis of clearly stated inclusion and exclusion criteria), randomization, interventions, lifestyle (habitual energy expenditure or diet), descriptions of patients lost to follow-up (studies with $>10 \%$ dropout without characteristics reported scored 0 ), details of HIIT protocol (type and training duration), main findings, statistical method, assessment method accuracy and adverse events. If the answer to an item was 'yes', the item score was 1; if it was 'no' or 'unable to determine' the score was zero. If an item was unable to be determined, it was scored as zero. The highest possible score for quality was 19 . The quality score of the studies was based on tertiles, for which 0-6 points is considered low quality, 6-12 points medium quality and 13-19 points high quality.

\subsection{Statistical analysis}

After extraction, the data were compiled into software designed specifically for meta-analyses (Comprehensive Meta-Analysis, version 2; Biostat, Englewood, NJ, USA). Data included were sample size, and pre- and post-intervention values. The standardized mean differences (paired SMD) were calculated to determine Cohen's $d$ for each study, and Hedges' $g$ was used to account for potential bias in small sample sizes. Effect sizes were calculated with a random-effects model (DerSimonian and Laird approach) that accounts for true variation in effects occurring from study to study and for random errors within a single study. The random-effects model was preferred to a fixed-effect model because certain experimental parameters had wide variation. The effect sizes were interpreted according to Cohen: $<0.2$, trivial; 0.20.3 , small; 0.5, moderate; and >0.8, large (Cohen, 1992). A negative effect size value indicated that exercise decreased outcomes while a positive effect size value indicated that exercise increased outcomes. The Iš index was used to measure heterogeneity with 25\%, 50\% and $75 \%$ indicating low, moderate and high heterogeneity, respectively. To test sensitivity and whether results were biased by a particular study the analyses were conducted by excluding one study at a time. Funnel plots were used to assess publication bias. In the absence of bias, studies would normally be distributed evenly around the mean effect size because of random sampling error.

\section{3 | RESULTS}

\subsection{Study selection}

The search strategy identified 803 non-duplicate articles from electronic databases; 723 publications were excluded after title and/or abstract analysis. Of the remaining articles, 80 fulfilled our inclusion criteria. The total number of publications finally included in the metaanalysis was 38: 37 for total mass, 28 for total FM, 11 for abdominal FM and 8 for visceral FM (Figure 1). The mean quality score obtained after evaluation of each trial included in our meta-analysis was $14.5 \pm 2.3$. Most of the studies were of high quality, having a score above 15 points.

Subject characteristics are summarized in Table 1. Overall, 959 subjects were included in the meta-analysis. In accordance with the 

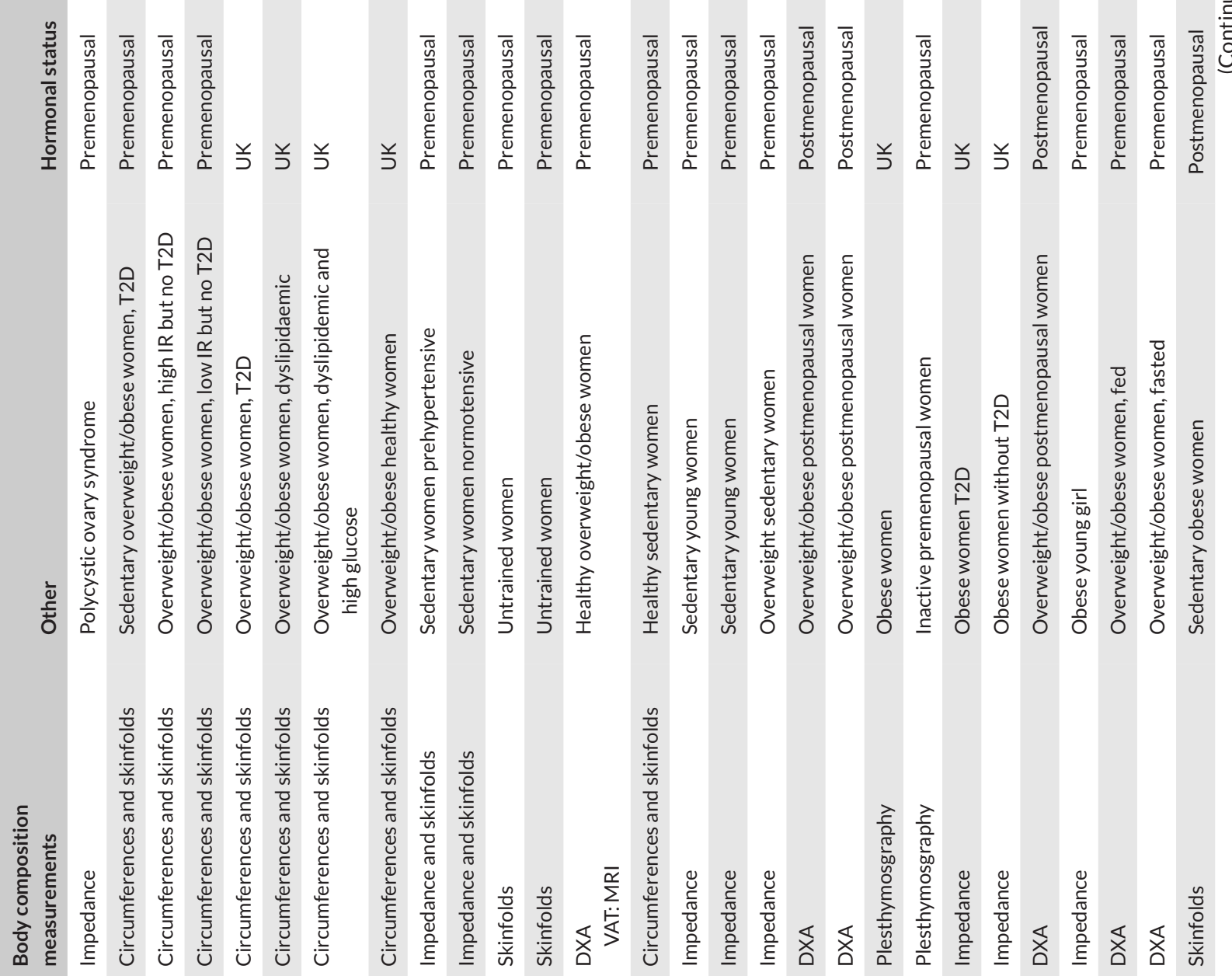

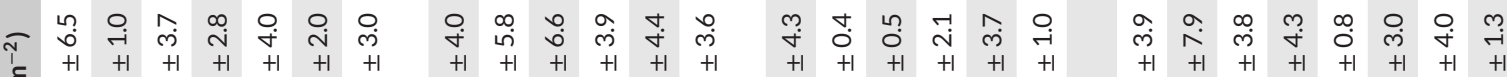

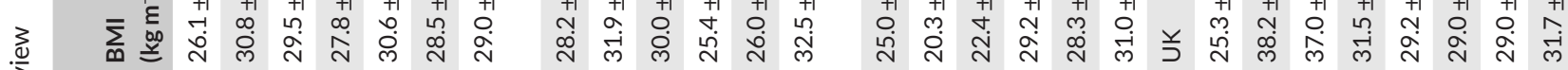

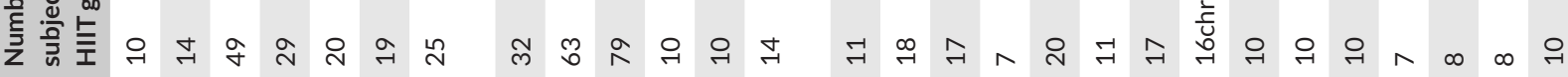

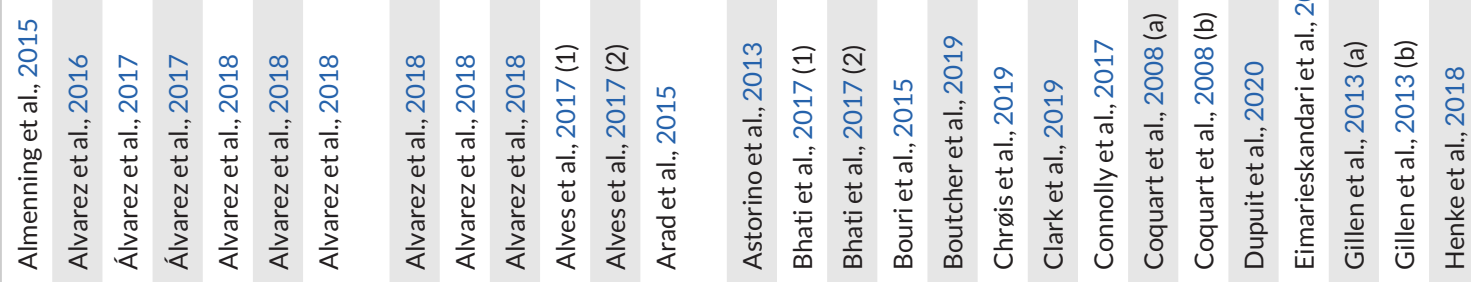




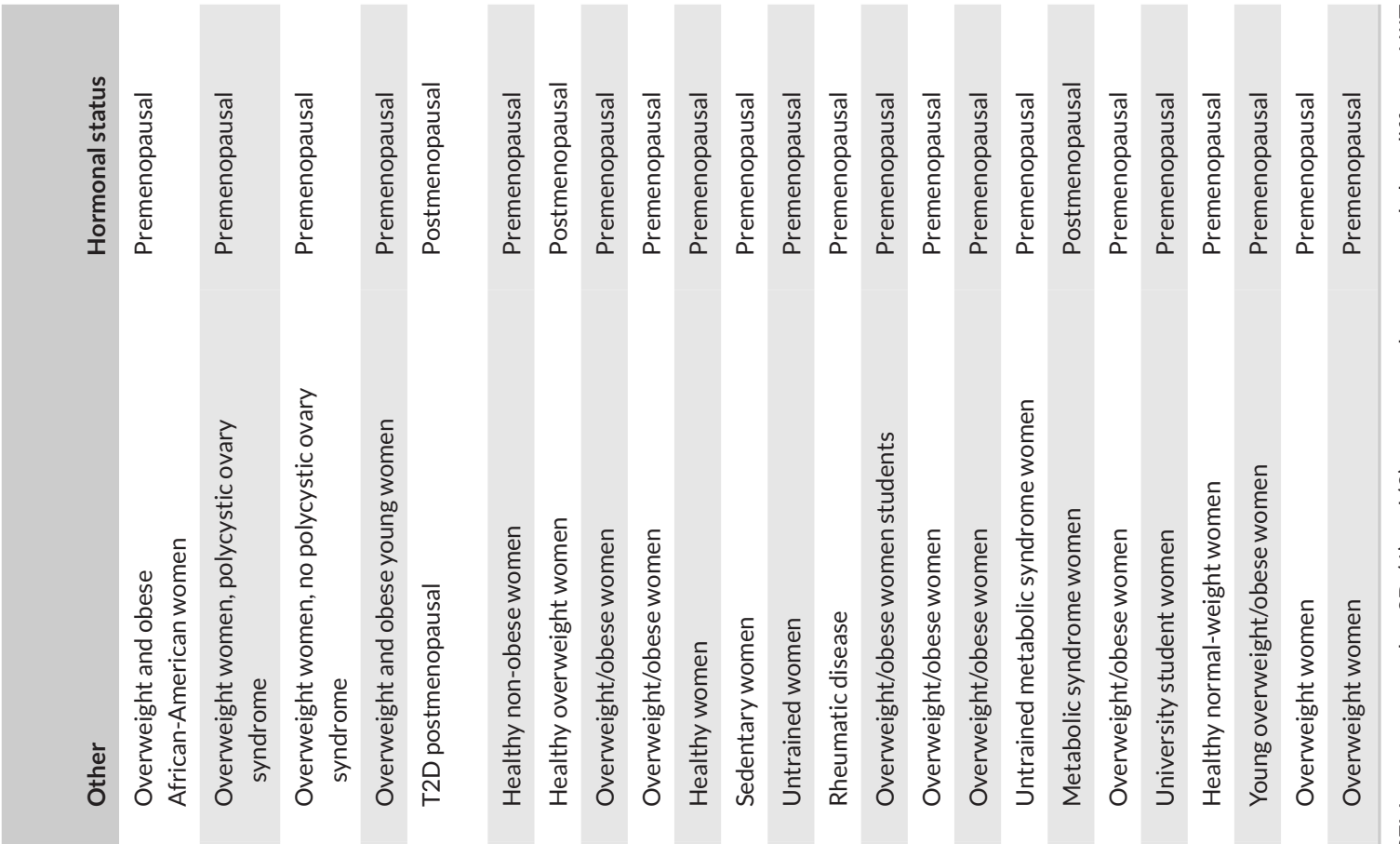

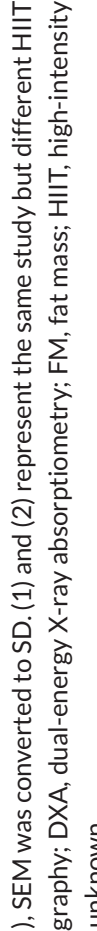

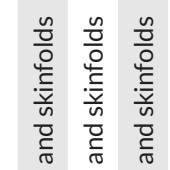

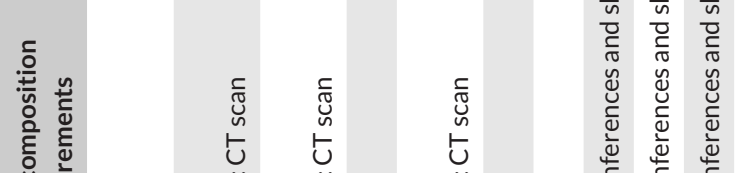

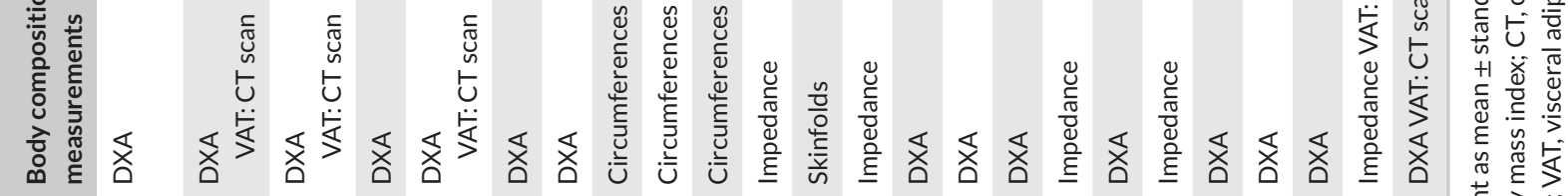

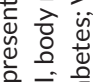

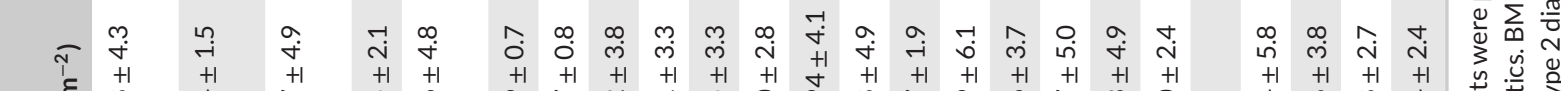

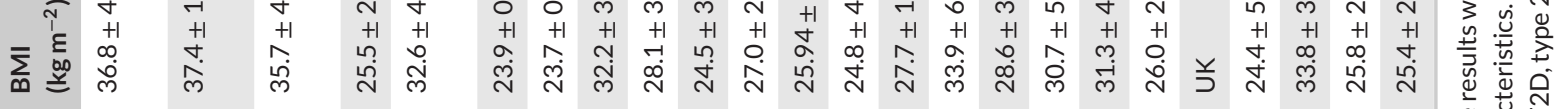

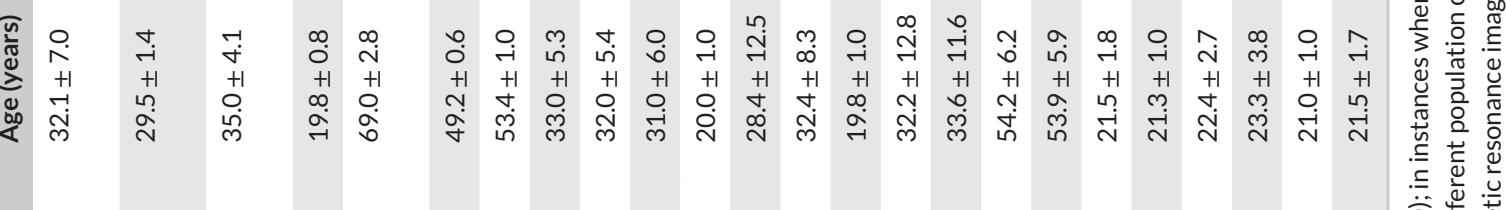
迹莡

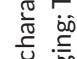

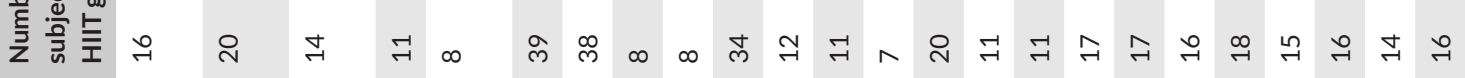
岛 ᄃ 节悉 荌

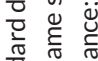

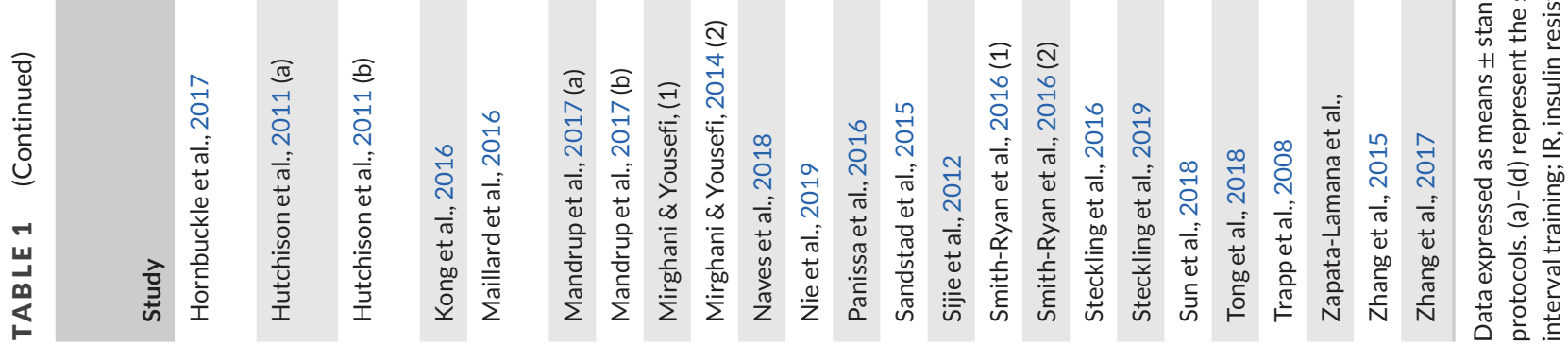


inclusion criteria, women were adults, with a mean age ranging from $19.8 \pm 0.8$ to $69.0 \pm 2.8$ years. All studies except five had recruited overweight or obese women, whose body mass index (BMI) ranged from $20.3 \pm 0.4$ to $38.2 \pm 7.9 \mathrm{~kg} \mathrm{~m}^{-}$š. Some women had diseases that could have influenced the effects of physical activity: type 2 diabetes $(n=4)$, dyslipidaemia ( $n=1)$, polycystic ovary syndrome $(n=2)$, hormonal state (menopause) $(n=6)$, metabolic syndrome $(n=2)$ and rheumatic disease $(n=1)$.

\subsection{Hormonal status of the women}

Most studies ( $n=33$ ) were performed in premenopausal women but generally without any details concerning the period of the menstrual cycle or the use of contraceptive pills. Two studies did not give any information about the hormonal status of the women (i.e. pre- or postmenopausal) (Table 1). Thus, only seven studies in our analysis included postmenopausal women.

\section{3 | Body composition assessments}

Fifteen studies used dual-energy $\mathrm{X}$-ray absorptiometry to determine whole body FM (Table 1). Other studies used less accurate and/or repeatable methods such as impedance $(n=11)$, plethysmography $(n=2)$ or circumference and skinfold measurements $(n=9)$, the last of which was recognized as the least reliable. Computed tomography (CT) and magnetic resonance imaging (MRI) were widely used to assess abdominal or visceral FM. The most recent DXA scans can also measure abdominal FM in different anatomical regions and estimate visceral FM content (Sawyer et al., 2016).

\subsection{HIIT programme characteristics}

The HIIT programmes are described in Table 2. Twenty-six HIIT studies used cycling and 12 running, with one offering a choice between the two. Only one study tested an elliptical type. The most widely used protocol consisted of alternate bouts of $4 \mathrm{~min}$ at high intensity followed by 3 min of recovery $(n=13)$. Other programmes used shorter times ( 8 s or $1 \mathrm{~min}$ ) at high intensity. When specified, recovery was generally active in all studies. The programmes ranged in duration from 3 to 16 weeks but usually lasted at least 10 weeks. In terms of frequency, most studies used three sessions a week $(n=32)$, lasting $<8$ weeks $(n=6)$ or $\geq 8$ weeks $(n=33)$.

\section{5 | Meta-analysis}

\subsubsection{Influence of HIIT on body weight, total FM and (intra)-abdominal FM and impact of hormonal status (before and after menopause)}

Overall, HIIT interventions decreased weight (effect size (ES): -0.19 (95\% Cl: -0.30 to -0.09$), P<10^{-3}$ ), total FM (ES: $-0.30(95 \% \mathrm{Cl}$ :
-0.43 to -0.17 ), $P<10^{-3}$ ), abdominal FM (ES: -0.22 ( $95 \% \mathrm{Cl}:-0.42$ to -0.02$), P<0.03$ ) but only tended to reduce visceral adipose tissue (ES: -0.25 (95\% Cl: -0.53 to 0.03 ), $P=0.078$ ) (Figure 2).

Stratified analysis of hormonal status showed a decrease in body weight after HIIT in premenopausal women (ES: -0.22 (95\% Cl: -0.35 to -0.10$), P<0.001$ ) but not in postmenopausal women (ES: -0.09 (95\% Cl: -0.35 to 0.18 ), $P=0.51$ ) (Figure $2 a$ ). Total FM was significantly reduced in premenopausal women (ES: $-0.23(95 \% \mathrm{Cl}:-0.48$ to -0.03$)$, $P<0.001)$ whereas only a trend was observed in postmenopausal women ( $P=0.079$ ) (Figure $2 b$ ). HIIT-induced abdominal FM loss was observed only in premenopausal women $(P=0.021)$ (Figure $2 c)$. HIIT tended to reduce visceral abdominal adiposity in premenopausal women $(P=0.06)$, but no effect was observed in postmenopausal women (Figure $2 \mathrm{~d}$ ).

\subsection{2 | Influence of BMI on HIIT-induced body composition changes}

Both normal weight (ES: -0.61 (95\% Cl: -0.87 to -0.35$), P<0.001$ ) and overweight/obese (ES: -0.20 ( $95 \% \mathrm{Cl}:-0.35$ to -0.05$), P=0.01)$ women lost total FM with HIIT programmes (data not shown). Overall, HIIT impact on total FM differed according to BMI with a greater effect on overweight/obese than on normal weight women $(P=0.011)$. This subanalysis had in fact to be limited to premenopausal women (analysis in this subgroup: $\mathrm{ES}:-0.25$ ( $95 \% \mathrm{Cl}:-0.43$ to -0.06$), P=0.009$ ) since all the studies performed with postmenopausal women included overweight or obese subjects.

HIIT was only effective in decreasing abdominal FM in women with an excess of weight at baseline (ES: -0.22 ( $95 \% \mathrm{Cl}$ : -0.43 to -0.01 ), $P=0.043)$. For the same reason as above, this result is restricted to premenopausal women (ES: -0.29 ( $95 \% \mathrm{Cl}:-0.56$ to -0.02$), P=0.033$ ).

\subsection{3 | Effect of HIIT type on body composition changes}

Although both modalities were effective $(P<0.001)$, stratified analysis comparing exercise type showed that cycling $(P=0.007)$ was more effective than running $(P=0.01)$ in reducing body weight (data not shown). Concerning total FM, the analysis showed that only cycling was effective in reducing total FM (ES: -0.34 (95\% Cl: -0.49 to -0.19$)$, $P<0.001$ ) and that for running simply a trend was observed (ES: -0.21 (95\% Cl: -0.46 to 0.04$), P=0.09$ ) (Figure 3). When pre- and postmenopausal women were separated into two distinct groups and subdivided according to exercise mode, the same conclusions emerged in each group. However, the trend for running was more pronounced in premenopausal women $(P=0.053)$ and was not observed in postmenopausal women $(P=0.957)$.

Only cycling reduced abdominal FM (ES: -0.27 (95\% Cl: -0.50 to $-0.04), P=0.02$ ) whereas no effect was found in running protocols (ES: -0.08 (95\% Cl: -0.49 to 0.33 ), $P=0.69$ ) (data not shown). No HIIT effect was observed with cycling (ES: -0.20 (95\% Cl: -0.54 to 0.14), 
TABLE 2 HIIT protocol details

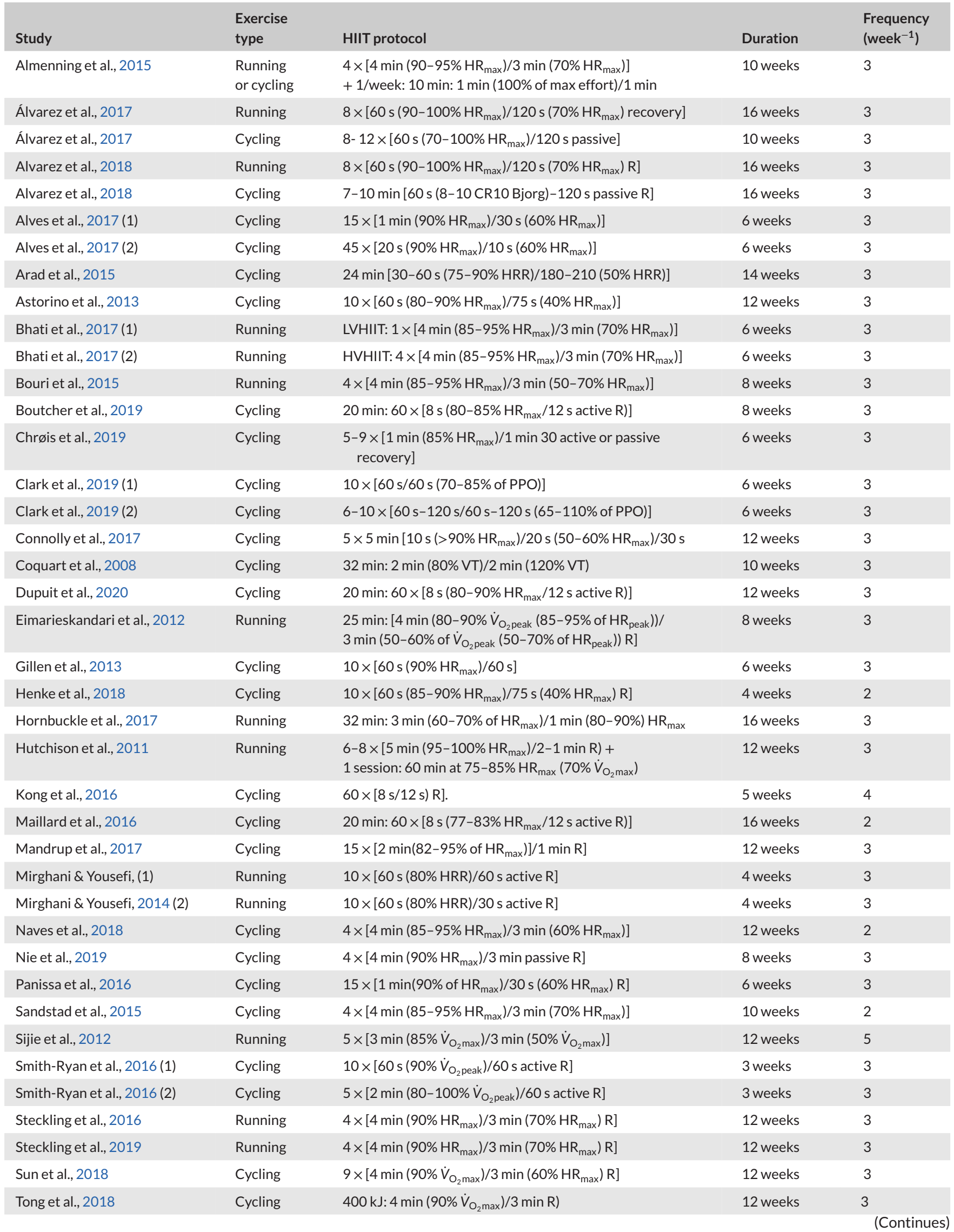


TABLE 2 (Continued)

\begin{tabular}{|c|c|c|c|c|}
\hline Study & $\begin{array}{l}\text { Exercise } \\
\text { type }\end{array}$ & HIIT protocol & Duration & $\begin{array}{l}\text { Frequency } \\
\left(\text { week }^{-1} \text { ) }\right.\end{array}$ \\
\hline Trapp et al., 2008 & Cycling & $20 \mathrm{~min}: 60 \times(8 \mathrm{~s} / 12 \mathrm{~s})$ & 15 weeks & 3 \\
\hline Zhang et al., 2015 & Running & $\begin{array}{l}4 \times\left[4 \min (85-95 \%) H R_{\text {peak }}\right) / 3 \min \left(50-60 \% \mathrm{HR}_{\text {peak }}\right) \\
\text { with } 7 \text { min rest between sets }\end{array}$ & 12 weeks & 4 \\
\hline
\end{tabular}

(1) and (2) represent the same study but different HIIT protocols. HIIT, high-intensity interval training; HR, heart rate; HRR, heart rate reserve; HV HIIT, High volume high-intensity interval training; LV HIIT, Low Volume high-intensity interval training; PPO, peak power output; R, recovery; $\dot{V}_{\mathrm{O}_{2}}$, oxygen consumption; $\mathrm{VT}$, ventilatory threshold.

$P=0.24)$ or with running programmes (ES: $-0.35(95 \% \mathrm{Cl}:-0.84$ to $0.14), P=0.16$ ) on the reduction of visceral FM. The same conclusions emerged for abdominal and visceral FM loss in premenopausal women (data not shown) and were not applicable to postmenopausal women.

\subsection{4 | Effect of HIIT programme duration on body composition changes}

Only studies using three sessions a week were retained in this analysis. Comparison of the duration of HIIT programmes showed that only training interventions longer than 8 weeks had significant effects on body weight (ES: -0.21 (95\% Cl: -0.34 to -0.09 ), $P<0.001$ ) (Figure 4a). While interventions shorter than 8 weeks are effective in reducing total FM (ES: -0.27 ( $95 \% \mathrm{Cl}:-0.52$ to -0.03 ), $P=0.03$ ), the effects are greater when training comprises or exceeds 8 weeks (ES: -0.33 (95\% Cl: -0.49 to -0.17 ), $P<0.001$ ) (data not shown). Only interventions $\geq 8$ weeks significantly reduced abdominal FM (ES: -0.28 (95\% Cl: -0.51 to -0.04$), P=0.02$ ) (Figure $4 b$ ). Training duration had no effect on visceral FM.

As only one study performed with postmenopausal women lasted less than 8 weeks, the significance of these results is predominantly applicable to premenopausal women.

\subsection{5 | Body composition assessments}

Total FM loss was significant when DXA $(P<0.001)$ or bioelectrical impedance analysis $(P=0.01)$ was used as the measurement method but not with plethysmography or the skinfold test (Figure $5 \mathrm{a}$ ). Only CT (ES: -0.47 (95\% Cl: -0.84 to -0.09$), P=0.015)$ detected reductions in abdominal FM after HIIT programmes (Figure 5b).

\section{4 | DISCUSSION}

The present study is the first meta-analysis to assess the effect of HIIT on body weight, total FM and (intra)-abdominal FM losses in women and is also the first to compare these effects before and after menopause. The analysis involved 959 women aged between
$19.8 \pm 0.8$ and $69 \pm 2.8$ years, with a BMI between $20.3 \pm 0.4$ and $38.2 \pm 7.9 \mathrm{~kg} \mathrm{~m}^{-2}$. Our results showed that HIIT programmes, especially cycling interventions, of a duration of at least 8 weeks are effective in reducing total and (intra)-abdominal FM in normal weight and overweight/obese women. The effects of HIIT were more evident in pre- than in postmenopausal women.

Premenopausal women accumulate fat in a metabolically healthier gluteo-femoral pattern than men, which lowers their risk of metabolic syndrome development (Wajchenberg et al., 2000). After menopause, women experience a significant increase in total FM and a redistribution of adipose tissue, which leads to increased abdominal fat deposition (Rettberg et al., 2014). Importantly, the abdominal FM gain in postmenopausal women tends to be visceral and not subcutaneous (Lovejoy et al., 2008), which is detrimental since visceral FM is known to be the most dangerous with regard to CVD risks (Wajchenberg et al., 2000). If the mechanisms of the increase in total and visceral FM during menopause are still not clearly elucidated, one potential candidate is probably the rapid fall in oestrogen levels (Kozakowski et al., 2017). Firstly oestrogens activate catabolic and anorexigenic signals in the brain, similar to those recruited by the anti-obesity hormone leptin (Gao et al., 2007). Secondly, it has been demonstrated that oestrogens increase fat oxidation in skeletal muscle and inhibit hepatic and muscle lipogenesis (Foryst-Ludwig et al., 2010). Finally, oestradiol (the predominant oestrogen) when binding to oestrogen receptor $\alpha$ (ER $\alpha)$ inhibits adrenaline-stimulated lipolysis in human subcutaneous fat cells by increasing the number of $\alpha 2$-adrenergic anti-lipolytic receptors (Pedersen et al., 2004). This could explain how oestrogens are related to typical female subcutaneous adipose tissue distribution before menopause because visceral fat deposits are not subject to the same inhibition. In addition, it was found that activation of the ER $\alpha$ receptors could stimulate adrenergic $\beta$ receptors in the visceral tissue, enhancing the process of lipolysis and in this way reducing abdominal FM in premenopausal women (Kozakowski et al., 2017). These observations explain why oestrogen deficiency during menopause is associated with an increase in total FM and more specifically, in visceral FM (Babaei et al., 2017). Alongside these adaptations, postmenopausal women have a lower resting metabolic rate, a decrease in total energy expenditure, and reduced of fat oxidation during prolonged exercise (Gavin, Kohrt, Klemm, \& Melanson, 2018; Poehlman et al., 2002). Here again, oestrogen deficiency probably plays a central role by 
(a) Study

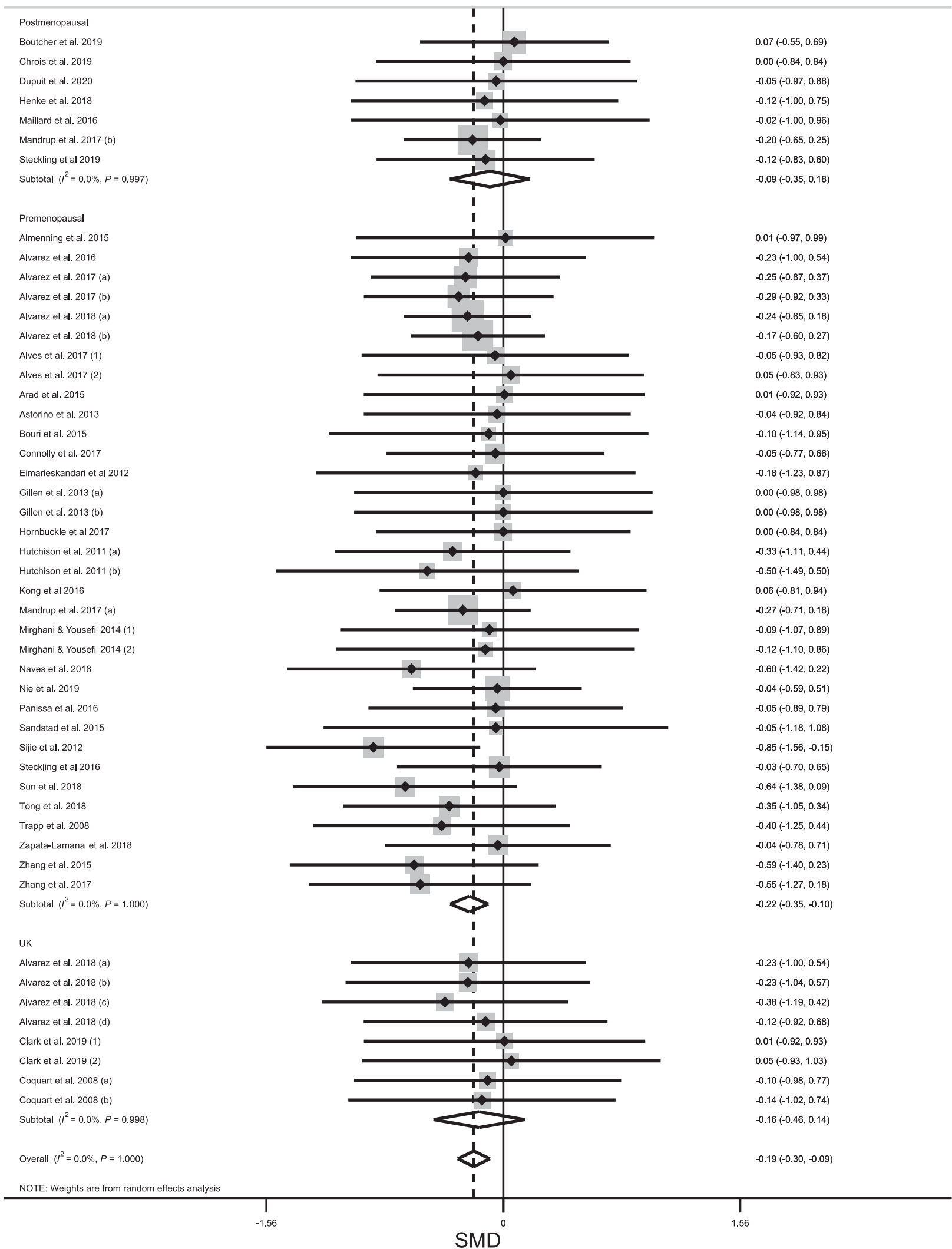

FIGURE 2 Forest plot for the effect of high-intensity interval training on body weight (kg) (a), total fat mass (b), abdominal fat mass (c) and visceral fat mass (d) with stratified analysis of hormonal status. (1) and (2) represent the same study but different HIIT protocols. (a)-(d) represent the same study but different population characteristics. (§) and (§§) represent the same study but different analyses of abdominal fat mass. UK: unknown (hormonal status) 
(b) Study

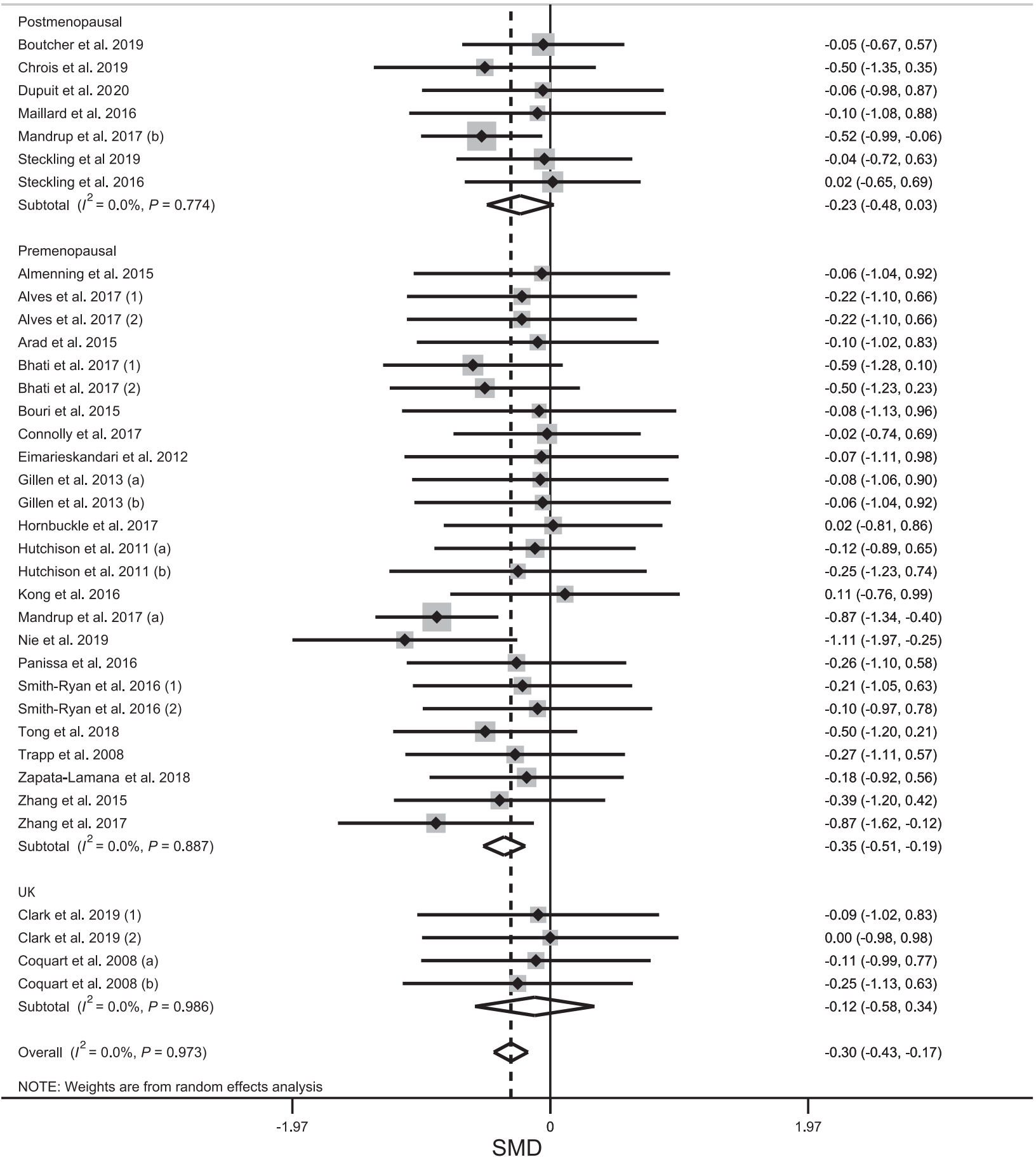

FIGURE 2 Continued

decreasing fat-free mass including muscle mass (Douchi et al., 2002), by decreasing energy expenditure and regulating brown fat activity (Gavin et al., 2018), and by promoting carbohydrate oxidation rates during prolonged exercise (Isacco \& Boisseau 2017). Thus, overall, the lack of oestrogens associated with menopause predisposes women to an excess of body fat including visceral FM (Lovejoy et al., 2008) and could alter regular exercise-induced FM loss (Isacco \& Boisseau 2017).
Although literature data show that the combination of diet and physical activity is the best way for promoting longer-term weight and/or FM loss (Verheggen et al., 2016), exercise alone can improve body composition if the energy expenditure leads finally to a negative energy balance (van Gemert et al., 2019; Verheggen et al., 2016). In the last position stand by the American College of Sports Medicine (ACSM) (Donnelly et al., 2009), moderate-intensity physical activity (between 150 and 250 min week ${ }^{-1}$ ) is recommended for preventing weight gain, 
(c) Study

ID

ES $(95 \% \mathrm{Cl})$

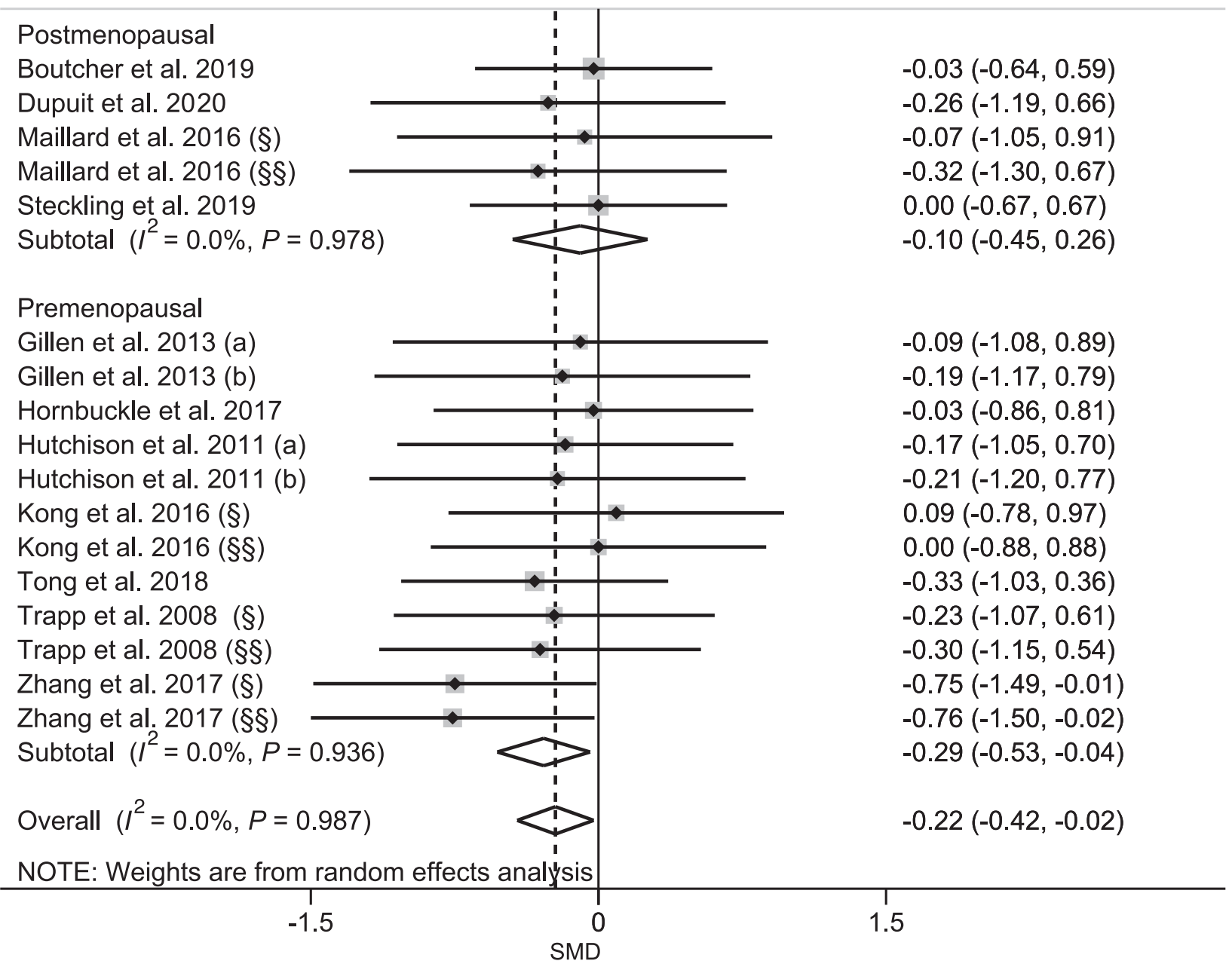

FIGURE 2 Continued

and more exercise for providing significant weight loss. Whatever the population involved, HIIT is now also recognized as a well-tolerated, safe and time-efficient strategy (Kessler et al., 2012; Taylor et al., 2017; Weston et al., 2014) to reduce body weight, total FM, and especially (intra)-abdominal adipose tissue (Maillard et al., 2018). As oestrogen deficiency promotes total and visceral FM gain, HIIT could be an interesting modality for women, particularly after menopause. All metaanalyses of the effects of HIIT on total and (intra)-abdominal FM loss were performed without distinction of sex except in the meta-analysis of Maillard et al., (2018) who stated that 'no sex-related effect was found for HIIT-induced reduction in total and abdominal or visceral FM'. However, the authors did not give any details on the hormonal status of the women, thereby overlooking the potential impact of oestrogen deficiency during menopause. Our review is thus the first to focus on the effects of HIIT on adipose tissue alterations in the female population and to consider separately these effects in pre- and postmenopausal women.
When all the women were pooled together, our meta-analysis confirmed that HIIT programmes significantly decrease body weight, total and abdominal FM and tend to reduce visceral FM in the female population. Both normal weight and overweight/obese women lost total FM after HIIT protocols whereas HIIT was only effective in decreasing abdominal FM in women with excess adiposity (BMI > 25). When pre- and postmenopausal women were separated from a stratified analysis, the effect of HIIT on weight and total FM was only significant before menopause (with a tendency after menopause for FM, $P=0.079$ ). Likewise, HIIT-induced abdominal FM loss was observed only in premenopausal women. From these results, HIIT could be suspected of being less effective in reducing adipose tissue in postmenopausal women. The mechanisms underlying HIIT-induced significant total and (intra)-abdominal FM loss are not completely elucidated but could partly be the result of increased catecholamine production, leading to significant lipolysis during exercise, followed by higher post-exercise fat oxidation (Maillard et al., 2018). As overall 
Study

ID

ES $(95 \% \mathrm{Cl})$

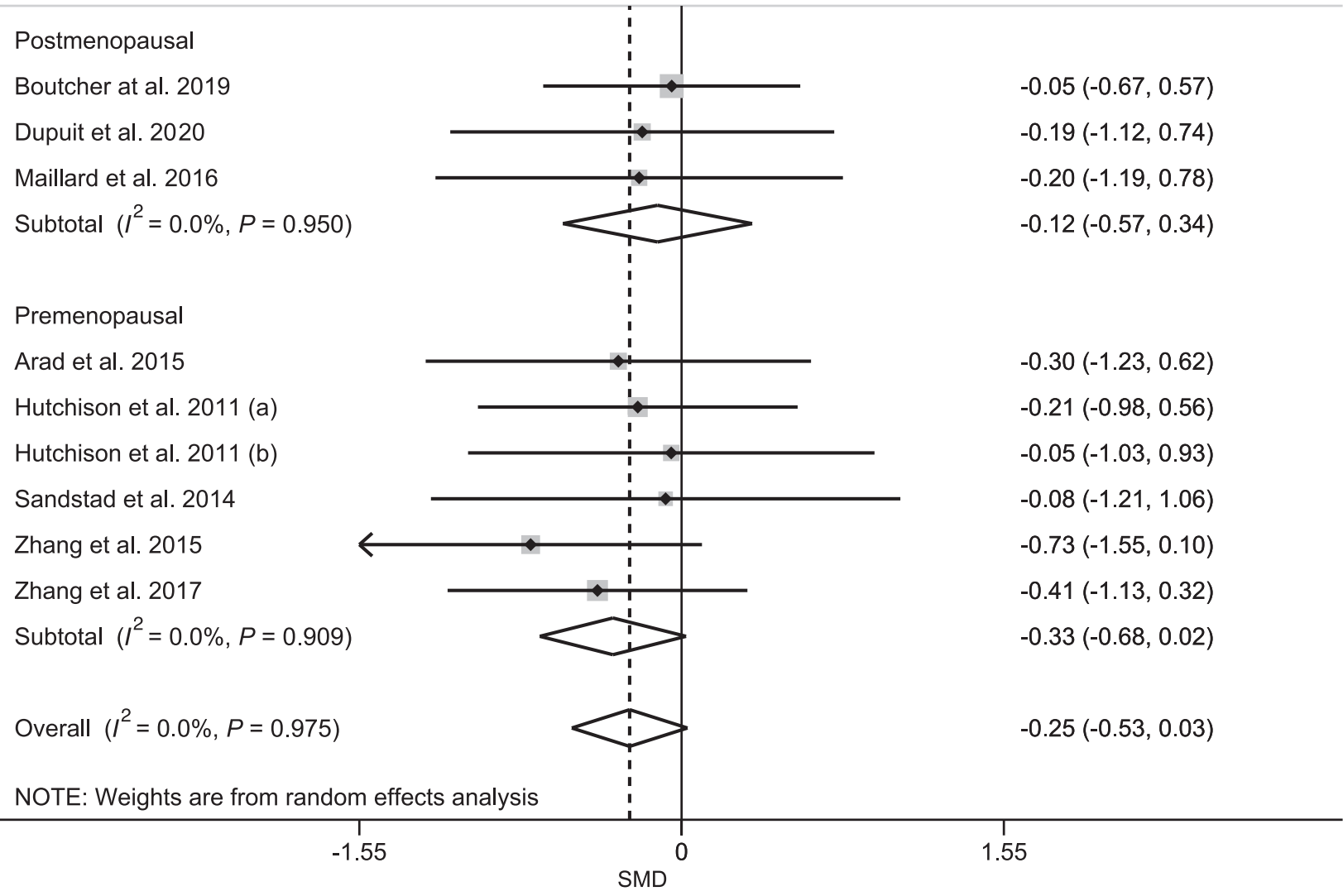

FIGURE 2 Continued

oestrogen deficiency decreases the proportion of lipid metabolism in energy supply during exercise and limits fat oxidation under resting conditions (Gavin et al., 2018; Isacco \& Boisseau 2017; Vieira-Potter et al., 2015), theoretically, postmenopausal women could lose less adipose tissue than premenopausal women after a few weeks of HIIT. However, the very small number of publications involving postmenopausal women makes interpretation difficult and further studies would be required for any definite conclusions to be drawn. A case in point is the report of Maillard et al., (2016), which showed that postmenopausal women performing a 16-week HIIT programme $(60 \times 8 \mathrm{~s}$ at $80-90 \%$ of peak heart rate, $12 \mathrm{~s}$ active recovery; 2 times a week) decreased their abdominal FM (DXA measurement from L1-L2 to the pubic rami). This finding emerged from a pre- vs. post-intervention comparison of two groups, one performing MICT and the other HIIT, using a two-way analysis of variance with repeated measures. When the HIIT group was considered separately, however, our stratified analysis failed to detect a HIIT-induced effect on abdominal FM loss in postmenopausal women. Another study performed by our laboratory also showed that a 12 -week HIIT programme $(60 \times 8 \mathrm{~s}$ at $80-90 \%$ of peak heart rate, $12 \mathrm{~s}$ active recovery) performed three times a week in 10 postmenopausal women resulted in a significant decrease in total $(-3.06 \% \pm 4.2)$ and abdominal $(-7.4 \% \pm 2.8) \mathrm{FM}$ (Dupuit et al., 2020). Thus, a larger sample of postmenopausal women would have been probably necessary to reach a significant threshold in this meta-analysis and more data would be needed to establish whether oestrogen deficiency requires a greater total amount of interval training to achieve a comparable remodelling of body composition.

Overall, our meta-analysis evidenced a significant effect of cycling HIIT on FM loss but only a trend appeared with running. Similarly, cycling HIIT was effective in reducing abdominal FM whereas no effect was found with running HIIT. When pre- and postmenopausal women were considered separately and studies subdivided according to exercise mode, the same conclusions emerged in each group. However, whereas the trend for running almost reached a level of significance for total FM in premenopausal women $(P=0.053)$, no effect was observed in postmenopausal women $(P=0.957)$. Running elicits a greater cardiorespiratory response $\left(\dot{V}_{\mathrm{O}_{2}}\right.$ and heart rate) than cycling during incremental and submaximal exercise, at matched relative and absolute workloads above and below the anaerobic threshold (Abrantes et al., 2012; Scott et al., 2006). However, when selecting running vs. cycling to perform a session of HIIT, workloads are inherently different (Kriel, Askew, \& Solomon, 2018). One possible explanation is that, at a similar percentage of maximal heart rate or $\dot{V}_{\mathrm{O}_{2} \max }$, there is a greater catecholamine release during cycling, which would lead to higher lipolysis via the activation of $\beta$-adrenergic 
Study

ID

ES $(95 \% \mathrm{Cl})$

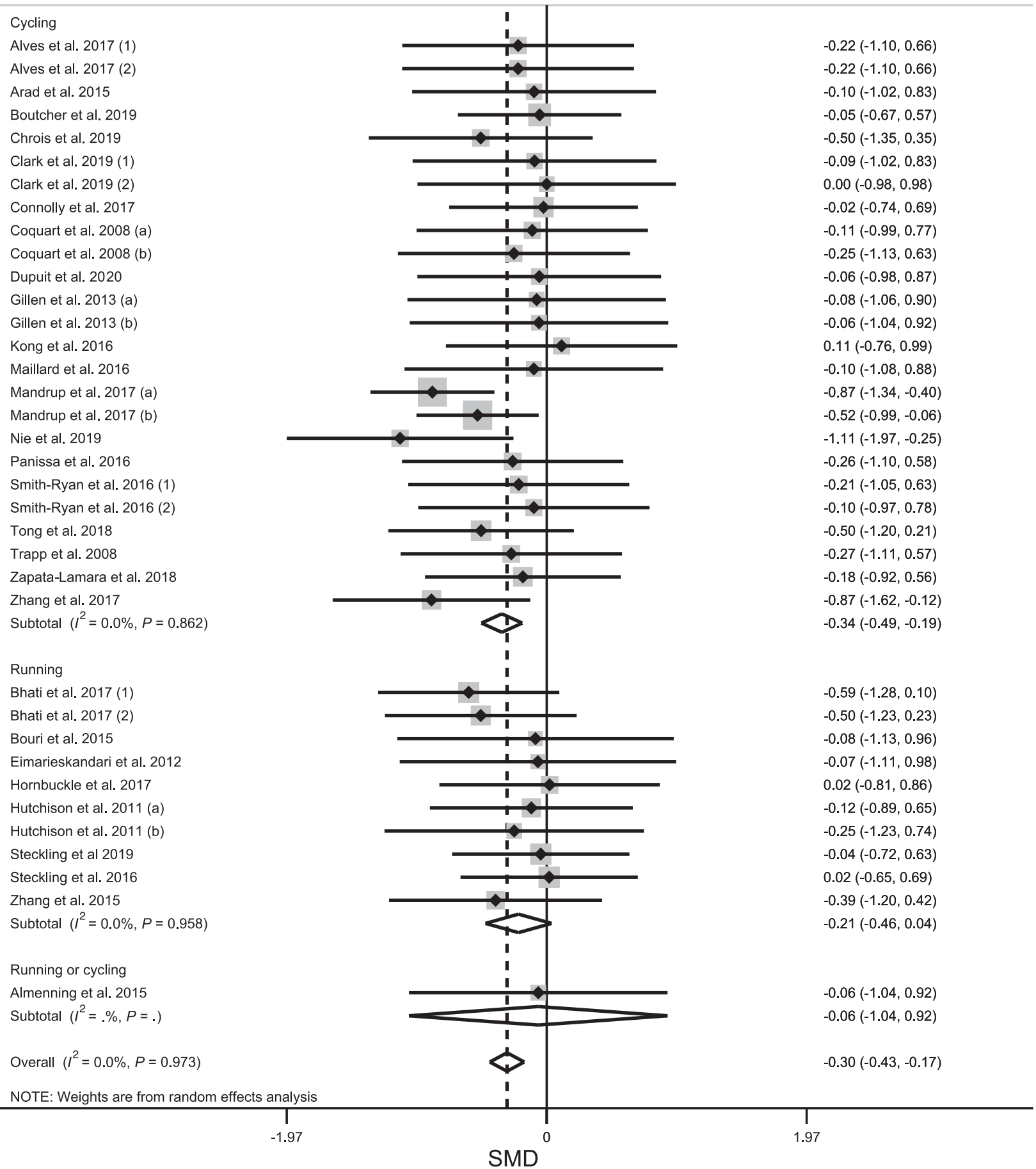

FIGURE 3 Forest plot for the effect of high-intensity interval training on total fat mass with stratified analysis of training type. (1) and (2) represent the same study but different HIIT protocols. (a) and (b) represent the same study but different population characteristics

receptors. However, Nieman et al., (1998) did not observe any greater catecholamine release in cycling vs. running protocols. In our metaanalysis, the heterogeneous nature of the HIIT programmes made the results difficult to interpret. In practical terms, however, it is possible that cycling is more suitable in sedentary women with overweight/obesity owing to the stress on joints caused by running and the lack of compliance sometimes observed with running programmes after the age of 50 years (Prakash et al., 2017).

Overall comparison of HIIT programmes comprising three sessions a week showed that only training interventions longer than 8 weeks had significant effects on body weight. Nevertheless, interventions shorter than 8 weeks were effective in reducing total FM (but to a lesser 
Study

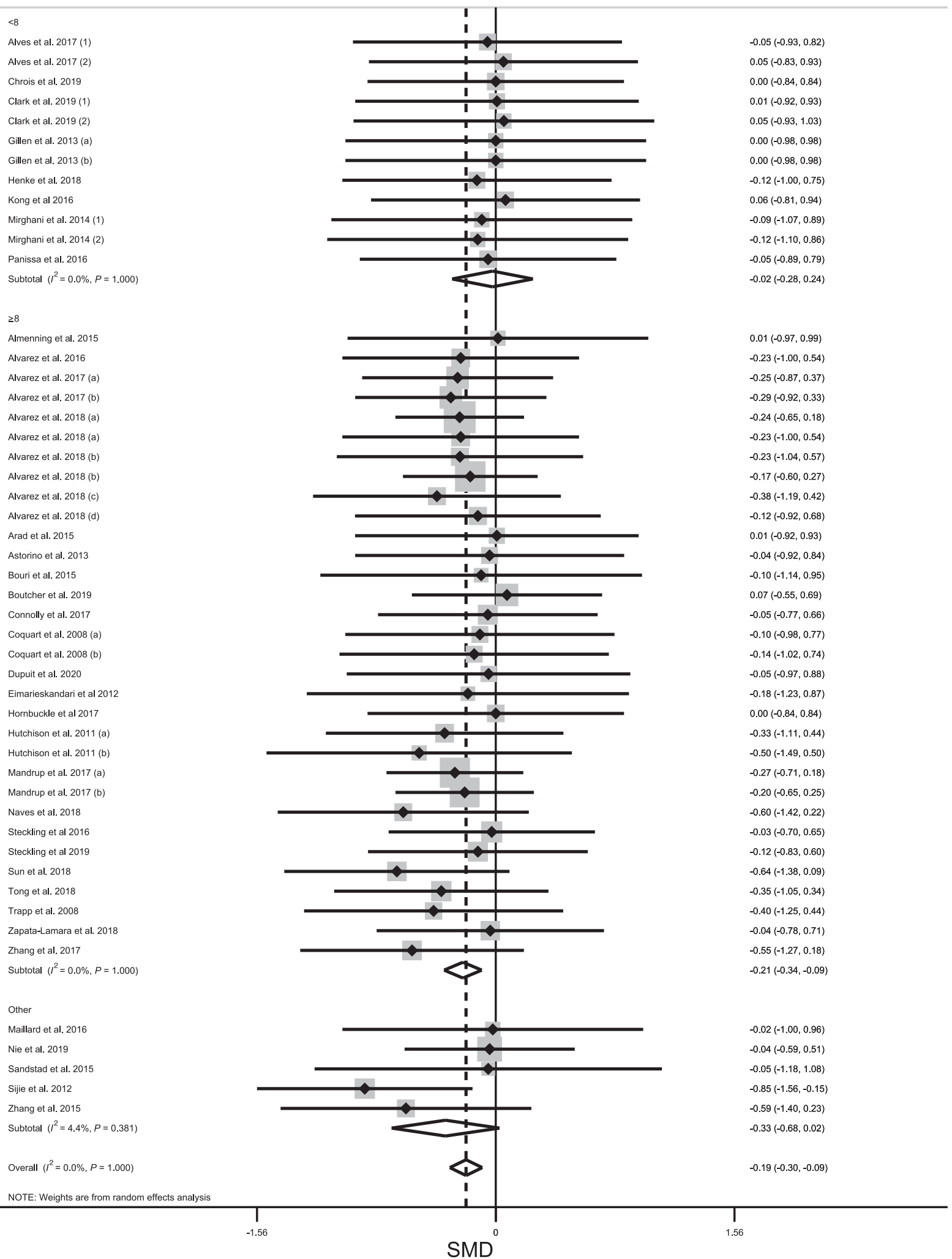

FIGURE 4 Forest plot for the effect of high-intensity interval training on body weight (kg) (a) and total fat mass (b) with stratified analysis of training duration $<8$ represents studies with three sessions a week for less than 8 weeks. $\geq 8$ represents studies with three sessions a week for 8 weeks or more. (1) and (2) represent the same study but different HIIT protocols. (a)-(d) represent the same study but different population characteristics. (§) and (§§) represent the same study but different analysis of abdominal fat mass. Other: studies that do not use three sessions per week 
Study

ID

ES $(95 \% \mathrm{Cl})$

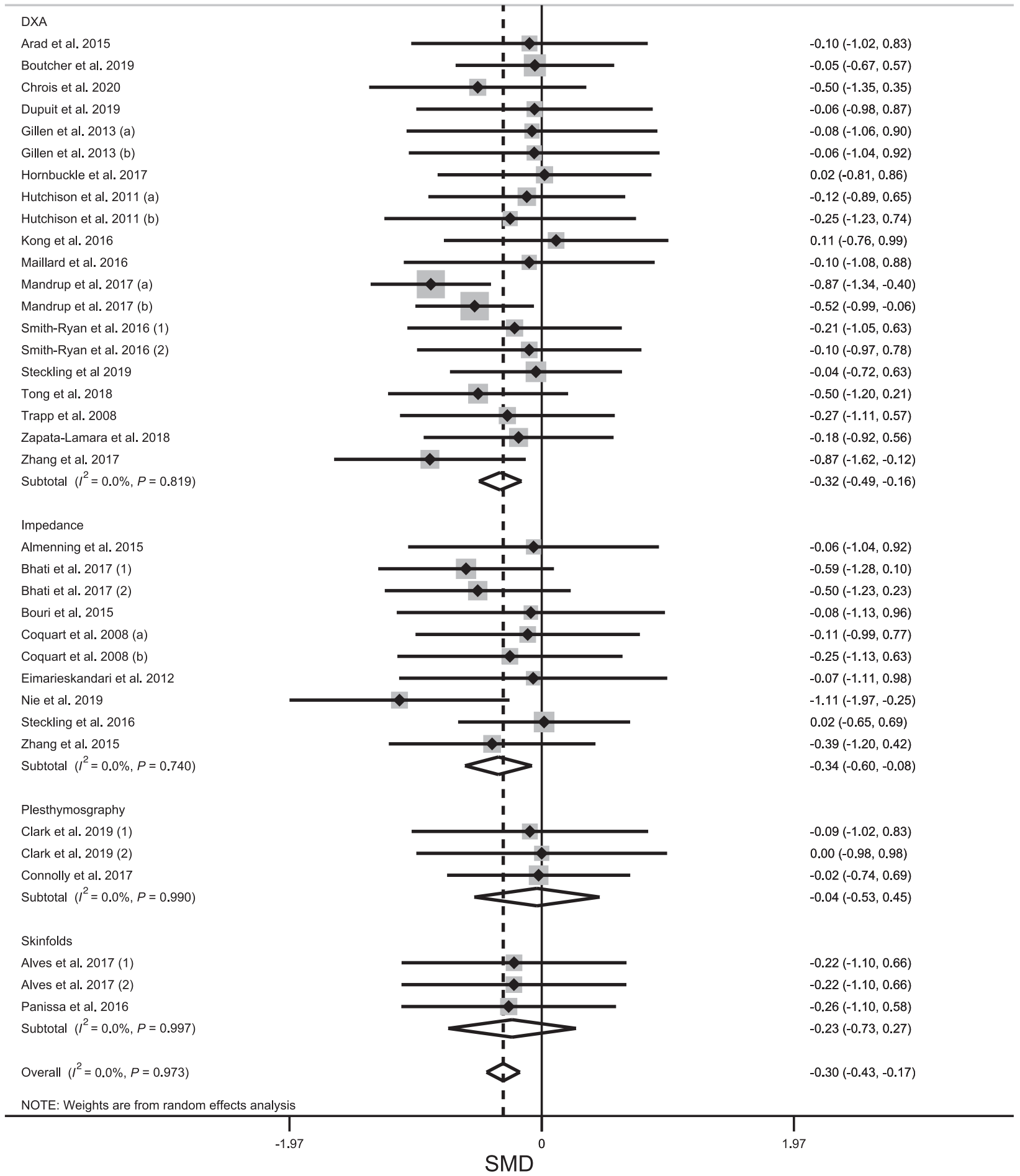

FIGURE 4 Continued

degree). In their meta-analysis, Batacan, Duncan, Dalbo, Tucker, and Fenning (2017) compared the effects of short-term HIIT ( $<12$ weeks) and long-term HIIT ( $\geq 12$ weeks). They concluded that at least 12 weeks of HIIT was necessary to improve body composition (reducing waist circumference and percentage of body fat) in overweight/obese populations. In contrast with this study, our results showed that shorter interventions were able to generate body composition remodelling, at least in premenopausal women. The same conclusion is not possible in postmenopausal women since only the study of Mandrup et al., (2017) fulfilled our inclusion criteria of three training sessions a week. 
Study

ID

ES $(95 \% \mathrm{Cl})$

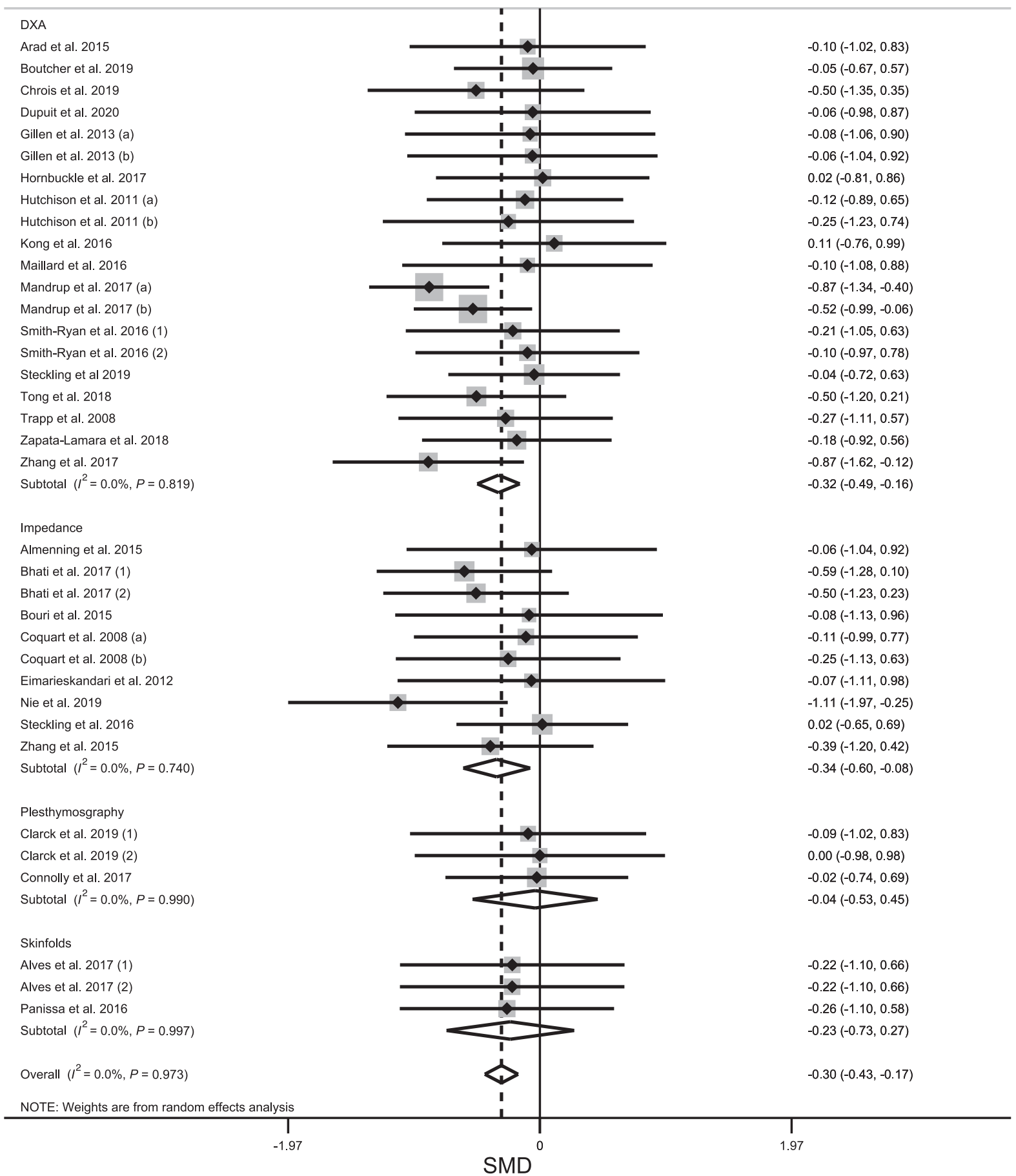

FIGURE 5 Forest plot for the effect of high-intensity interval training on total fat mass (a) and abdominal fat mass (b) with stratified analysis of body composition assessment. (1) and (2) represent the same study but different HIIT protocols. (a) and (b) represent the same study but different population characteristics. (§) and (§§) represent the same study but different analysis of abdominal fat mass

The last analysis of our review concerned the method used to assess body composition. DXA is a 'gold-standard' method for measuring total FM but is probably not the best for assessing abdominal and, more particularly, visceral FM (Bosch et al., 2015). While CT and MRI are probably the best methods to measure visceral adipose tissue (VAT) (Crabtree et al., 2019) evidence points to the potential usefulness of
DXA in providing accurate measurements of VAT in addition to total body composition determination in obese subjects (Bertin, Marcus, Ruiz, Eschard, \& Leutenegger, 2000). However, its accuracy seems to be lower in individuals with high VAT levels (Bosch et al., 2015). Thus, as already shown by Shuster, Patlas, Pinthus, and Mourtzakis (2012), it is important to select the most suitable method for each parameter. 
Study

ID

ES $(95 \% \mathrm{Cl})$

CT-scan or MRI

Hutchison et al. 2011 (a)

Hutchison et al. 2011 (b)

Maillard et al. 2016 (§)

Zhang et al. 2017 (§)

Zhang et al. 2017 (§§)

Subtotal $\left(I^{2}=0.0 \%, P=0.649\right)$

DXA

Boutcher et al. 2019

Dupuit et al. 2019

Gillen et al. 2013 (a)

Gillen et al. 2013 (b)

Hornbuckle et al. 2017

Kong et al. 2016 (§)

Kong et al. 2016 (§§)

Maillard et al. 2016 (§§)

Steckling et al. 2019

Tong et al. 2018

Trapp et al. 2008 (§)

Trapp et al. $2008(\S \S)$

Subtotal $\left(I^{2}=0.0 \%, P=1.000\right)$

Overall $\left(I^{2}=0.0 \%, P=0.987\right)$

NOTE: Weights are from random effects analysis',
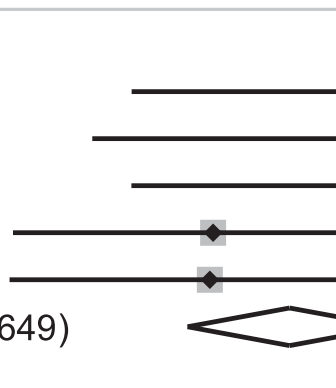

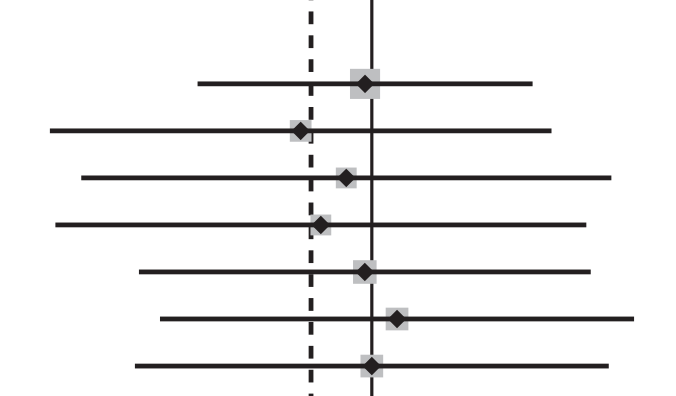

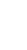

$-0.03(-0.64,0.59)$

$-0.26(-1.19,0.66)$

$-0.09(-1.08,0.89)$

$-0.19(-1.17,0.79)$

$-0.03(-0.86,0.81)$

$0.09(-0.78,0.97)$

$0.00(-0.88,0.88)$

$-0.32(-1.30,0.67)$

$0.00(-0.67,0.67)$

$-0.33(-1.03,0.36)$

$-0.23(-1.07,0.61)$

$-0.30(-1.15,0.54)$

$-0.13(-0.37,0.11)$

$-0.22(-0.42,-0.02)$

\section{$-1.5$}

overweight and obesity. In our review, the mean BMI was used to classify each population since only very few studies involved a specific population with a BMI superior or inferior at 25 or 30 . The use of $\mathrm{BMI}$ could also be a limitation since it does not reflect the percentage of FM or its localization, and its utilization seems less suitable with advancing age (De Lorenzo et al., 2020).

To compare the effects of the duration of HIIT, it was decided to analyse those studies with similar training frequencies, since a shorter programme duration can be offset by greater training frequency (and vice versa) (Stavrinou et al., 2018, 2019). In our meta-analysis, 33 of the 38 studies were carried out at a frequency of three times a week (i.e. $85 \%$ ), because HIIT performs once or twice per week can limit metabolic adaptations (Dalleck et al., 2010; Kavaliauskas et al., 2017; Stavrinou et al., 2018, 2019).

In our review, we included bioelectrical impedance $(n=14)$ and plethysmography $(n=2)$ in the analysis for measuring FM changes despite the limits of these methods (Brodie et al., 1998; Kuriyan, 2018; Mulasi et al., 2015). While DXA is considered to be the best method weight and overweight subjects, while others combined people with 
to determine whole-body FM, it has been shown that it does not accurately assess body composition in markedly obese women and that the level of hydration of the subjects can also alter total and/or regional FM measurements (Bredella et al., 2010; Barreira \& Tseh 2020).

Another limitation concerns the inclusion of menopausal women. In certain studies, the groups of women classified as menopausal comprised only those who actually were menopausal, i.e. with at least 12 months of amenorrhoea. In others, however, only the mean age of the group was given with no indication of hormonal status. Some of these groups with a relatively young mean age probably included women over 40-45 years old, who in our analysis were considered as pre-menopausal. Finally, the lack of information regarding cycling programmes, such as the cycle ergometer used, revolutions per minute, resistance, watts and heart rate, and running protocols, such as speed, gradient treadmill and heart rate, make it difficult to compare two modalities or studies using the same modality.

\section{5 | CONCLUSION}

This is the first meta-analysis to investigate the effects of HIIT on adipose tissue alterations in the female population and to analyse separately these effects in pre- and postmenopausal women. When all the women were pooled together, our results confirmed that HIIT programmes significantly decreased body weight and total and abdominal FM. Both normal weight and overweight/obese women lost total FM after HIIT protocols whereas HIIT was only effective in decreasing abdominal FM in women with excess adiposity. When pre- and postmenopausal women were considered separately, the effect of HIIT on weight, total and abdominal FM was only significant before menopause. Owing to the very small number of publications involving postmenopausal women, it is difficult to reach any definitive conclusions and further studies are still needed. Nevertheless, oestrogen deficiency could play a role in these discrepancies. Finally, from a practical point of view, cycling HIIT seemed more effective than running, especially in postmenopausal women, and training interventions longer than 8 weeks comprising three sessions a week should be encouraged whatever the hormonal status and the adiposity level of the participants.

\section{COMPETING INTERESTS}

None of the authors declares competing financial interests.

\section{AUTHOR CONTRIBUTIONS}

D.M., M.F. and N.B. wrote the manuscript, participated in data acquisition and interpretation. P.B. carried out statistical analysis, M.L.M. and A.L.H. participated in manuscript reviewing/revising. All authors have read and approved the final version of this manuscript and agree to be accountable for all aspects of the work in ensuring that questions related to the accuracy or integrity of any part of the work are appropriately investigated and resolved. All persons designated as authors qualify for authorship, and all those who qualify for authorship are listed.
ORCID

Bruno Pereira (D) https://orcid.org/0000-0003-3778-7161

Nathalie Boisseau (D) https://orcid.org/0000-0003-2835-1163

\section{REFERENCES}

Abildgaard, J., Pedersen, A. T., Green, C. J., Harder-Lauridsen, N. M., Solomon, T. P., Thomsen, C., ... Lindegaard, B. (2013). Menopause is associated with decreased whole body fat oxidation during exercise. American Journal of Physiology. Endocrinology and Metabolism, 304(11), E1227-E1236.

Abrantes, C., Sampaio, J., Reis, V., Sousa, N., \& Duarte, J. (2012). Physiological responses to treadmill and cycle exercise. International Journal of Sports Medicine, 33(01), 26-30. https://doi.org/10.1055/s-0031-1285928

Almenning, I., Rieber-Mohn, A., Garnaes, K. K., Lundgren, K. M., Lovik, T. S., \& Trine Moholdt, T. (2015). High intensity interval training versus strength training to improve cardiovascular risk factors in women with polycystic ovary syndrome. A randomized controlled trial. European Journal of Preventive Cardiology, 22(1), S23-S24.

Álvarez, C., Ramírez-Campillo, R, Ramírez-Vélez, R, Izquierdo, M. (2017). Prevalence of non-responders for glucose control markers after 10 weeks of high-intensity interval training in adult women with higher and lower insulin resistance. Frontiers in Physiology, 8, 479. Published 2017 Jul 6. https://doi.org/10.3389/fphys.2017.00479.

Alvarez, C., Ramirez-Campillo, R., Martinez-Salazar, C., Mancilla, R., FloresOpazo, M., Cano-Montoya, J., \& Ciolac, E. G. (2016). Low-volume highintensity interval training as a therapy for type 2 diabetes. International Journal of Sports Medicine, 37(9), 723-729.

Alvarez, C., Ramirez-Campillo, R., Martinez-Salazar, C., Castillo, A., Gallardo, F., \& Ciolac, E. G. (2018). High-intensity interval training as a tool for counteracting dyslipidemia in women. International Journal of Sports Medicine, 39(5), 397-406.

Alves, E. D., Salermo, G. P., Panissa, V. L. G., Franchini, E., \& Takito, M. Y. (2017). Effects of long or short duration stimulus during high-intensity interval training on physical performance, energy intake, and body composition. Journal of Exercise Rehabilitation, 13(4), 393-399.

Arad, A. D., DiMenna, F. J., Thomas, N., Tamis-Holland, J., Weil, R., Geliebter, A., \& Albu, J. B. (2015). High-intensity interval training without weight loss improves exercise but not basal or insulin-induced metabolism in overweight/obese African American women. Journal of Applied Physiology, 119(4), 352-362.

Astorino, T. A., Schubert, M. M., Palumbo, E., Stirling, D., \& McMillan, D. W. (2013). Effect of two doses of interval training on maximal fat oxidation in sedentary women. Medicine and Science in Sports and Exercise, 45(10), 1878-1886.

Babaei, P., Dastras, A., Tehrani, B. S.,\& Pourali Roudbaneh, S. (2017). The effect of estrogen replacement therapy on visceral fat, serum glucose, lipid profiles and apelin level in ovariectomized rats. Journal of Menopausal Medicine, 23(3), 182https://doi.org/10.6118/jmm.2017.23. 3.182.

Barreira, T. V., \& Tseh, W. (2020) The effects of acute water ingestion on body composition analyses via Dual-Energy X-Ray Absorptiometry. Clinical Nutrition, https://doi.org/10.1016/j.clnu.2020.03.037.

Batacan, R. B., Duncan, M. J., Dalbo, V. J., Tucker, P. S., \& Fenning, A. S. (2017). Effects of high-intensity interval training on cardiometabolic health: A systematic review and meta-analysis of intervention studies. British Journal of Sports Medicine, 51(6), 494-503.

Bertin, E., Marcus, C., Ruiz, J. C., Eschard, J. P., \& Leutenegger, M. (2000). Measurement of visceral adipose tissue by DXA combined with anthropometry in obese humans. International Journal of Obesity and Related Metabolic Disorders, 24(3), 263-270.

Bhati, P., Bansal, V., \& Moiz, J. A. (2017). Comparison of different volumes of high intensity interval training on cardiac autonomic function in sedentary young women. International Journal of Adolescent Medicine and Health, 31(6), https://doi.org/10.1515/ijamh-2017-0073. 
Bosch, T. A., Dengel, D. R., Kelly, A. S., Sinaiko, A. R., Moran, A., \& Steinberger, J. (2015). Visceral adipose tissue measured by DXA correlates with measurement by $\mathrm{CT}$ and is associated with cardiometabolic risk factors in children. Pediatric Obesity, 10(3), 172-179.

Bouri, S. Z., Peeri, M., \& Ali Azarbayjani, M. (2015). The effect of physical activity on adiponectin and osteocalcin in overweight young females. International Medical Journal, 22(1), 43-46.

Boutcher, S. H. (2011). High-intensity intermittent exercise and fat loss. Journal of Obesity, 2011, 868305.

Boutcher, Y. N., Boutcher, S. H., Yoo, H. Y., \& Meerkin, J. D. (2019). The effect of sprint interval training on body composition of postmenopausal women. Medicine and Science in Sports and Exercise, 51(7), 1413-1419.

Bredella, M. A., Ghomi, R. H., Thomas, B. J., Torriani, M., Brick, D. J., Gerweck, A. V., ... Miller, K. K. (2010). Comparison of DXA and CT in the assessment of body composition in premenopausal women with obesity and anorexia nervosa. Obesity, 18(11), 2227-2233. https://doi.org/10. 1038/oby.2010.5.

Brodie, D., Moscrip, V., \& Hutcheon, R. (1998). Body composition measurement: A review of hydrodensitometry, anthropometry, and impedance methods. Nutrition, 14(3), 296-310. https://doi.org/10.1016/ s0899-9007(97)00474-7.

Chrøis, K. M., Dohlmann, T. L., Søgaard, D., Hansen, C. V., Dela, F., Helge, J. W., \& Larsen, S. (2019). Mitochondrial adaptations to high intensity interval training in older females and males. European Journal of Sport Science, 20(1), 135-145.

Clark, A., De La Rosa, A. B., DeRevere, J. L., \& Astorino, T. A. (2019). Effects of various interval training regimes on changes in maximal oxygen uptake, body composition, and muscular strength in sedentary women with obesity. European Journal of Applied Physiology, 119(4), 879-888. https: //doi.org/10.1007/s00421-019-04077-x.

Cohen, J. (1992). A power primer. Psychological Bulletin, 112(1), 155-159.

Connolly, L. J., Bailey, S. J., Krustrup, P., Fulford, J., Smietanka, C., \& Jones, A. M. (2017). Effects of self-paced interval and continuous training on health markers in women. European Journal of Applied Physiology, 117(11), 2281-2293.

Coquart, J. B. J., Lemaire, C., Dubart, A.-E., Luttembacher, D.-P., Douillard, C., \& Garcin, M. (2008). Intermittent versus continuous exercise : Effects of perceptually lower exercise in obese women. Medicine and Science in Sports and Exercise, 40(8), 1546-1553.

Crabtree, C. D., LaFountain, R. A., Hyde, P. N., Chen, C., Pan, Y., Lamba, N., ... Simonetti, O. P. (2019). Quantification of human central adipose tissue depots: An anatomically matched comparison between DXA and MRI. Tomography, 5(4), 358-366.

Dalleck, L., Bushman, T. T., Crain, R. D., Gajda, M. M., Koger, E. M., \& Derksen, L. A. (2010). Dose-response relationship between interval training frequency and magnitude of improvement in Lactate Threshold. International Journal of Sports Medicine, 31(8), 567-571. https://doi.org/ 10.1055/s-0030-1254136.

De Lorenzo, A., Romano, L., Di Renzo, L., Di Lorenzo, N., Cenname, G., \& Gualtieri, P. (2020). Obesity: A preventable, treatable, but relapsing disease. Nutrition, 71, 110615.

Dolin, C. D., \& Kominiarek, M. A. (2018). Pregnancy in women with obesity. Obstetrics and Gynecology Clinics of North America, 45(2), 217-232.

Donnelly, J. E., Blair, S. N., Jakicic, J. M., Manore, M. M., Rankin, J. W., \& Smith, B. K.; American College of Sports Medicine.(2009) American College of Sports Medicine Position Stand. Appropriate physical activity intervention strategies for weight loss and prevention of weight regain for adults. Medicine and Science in Sports and Exercise, 41(2), 459-471.

Douchi, T., Yamamoto, S., Yoshimitsu, N., Andoh, T., Matsuo, T., \& Nagata, Y. (2002). Relative contribution of aging and menopause to changes in lean and fat mass in segmental regions. Maturitas, 42(4), 301-306. https://doi. org/10.1016/s0378-5122(02)00161-5.

Downs, S. H., \& Black, N. (1998). The feasibility of creating a checklist for the assessment of the methodological quality both of randomised and non- randomised studies of health care interventions. Journal of Epidemiology and Community Health, 52(6), 377-384.

Dupuit, M., Rance, M., Morel, C., Bouillon, P., Pereira, B., Bonnet, A., ... Boisseau, N. (2020). Moderate-intensity continuous training or highintensity interval training with or without resistance training for altering body composition in postmenopausal women. Medicine and Science in Sports and Exercise, 52(3), 736-745.

Eimarieskandari, R., Zilaeibouri, S., Zilaeibouri, M., \& Ahangarpou, A. (2012). Comparing two modes of exercise training with different intensity on body composition in obese young girls. Ovidius University Annals, Series Physical Education and Sport/Science, Movement and Health, 12(2), 473478.

Foryst-Ludwig, A., \& Kintscher, U. (2010). Metabolic impact of estrogen signalling through ERalpha and ERbeta. The Journal of Steroid Biochemistry and Molecular Biology, 122(1-3), 74-81. https://doi.org/10.1016/j.jsbmb.2010.06.012.

Gao, Q., Mezei, G., Nie, Y., Rao, Y., Choi, C. S., Bechmann, I., ... Horvath, T. L. (2007). Anorectic estrogen mimics leptin's effect on the rewiring of melanocortin cells and Stat 3 signaling in obese animals. Nature Medicine, 13(1), 89-94. https://doi.org/10.1038/nm1525.

Gavin, K. M., Kohrt, W. M., Klemm, D. J., \& Melanson, E. L. (2018). Modulation of energy expenditure by estrogens and exercise in women. Exercise and Sport Sciences Reviews, 46(4), 232-239.

Gillen, J. B., Percival, M. E., Ludzki, A., Tarnopolsky, M. A., \& Gibala, M. J. (2013). Interval training in the fed or fasted state improves body composition and muscle oxidative capacity in overweight women. Obesity, 21(11), 2249-2255.

Hassan, M., Latif, N., \& Yacoub, M. (2012). Adipose tissue: Friend or foe? Nature Reviews Cardiology, 9(12), 689-702.

Henke, E., Oliveira, V. S., da Silva, I. M., Schipper, L., Dorneles, G., Elsner, V. R., ... Peres, A. (2018). Acute and chronic effects of high intensity interval training on inflammatory and oxidative stress markers of postmenopausal obese women. Translational Sports Medicine, 1(6), 257-264.

Hornbuckle, L. M., McKenzie, M. J., \& Whitt-Glover, M. C. (2017). Effects of high-intensity interval training on cardiometabolic risk in overweight and obese African-American women: A pilot study. Ethnicity \& Health, 23(7), 752-766.

Hutchison, S. K., Stepto, N. K., Harrison, C. L., Moran, L. J., Strauss, B. J., \& Teede, H. J. (2011). Effects of exercise on insulin resistance and body composition in overweight and obese women with and without polycystic ovary syndrome. Journal of Clinical Endocrinology and Metabolism, 96(1), 48-56.

Isacco, L., \& Boisseau, N. (2017). Sex hormones and substrate metabolism during endurance exercise. In A. C. Hackney (Ed.), Sex hormones, exercise and women: Scientific and clinical aspects (pp. 35-58). Cham: Springer International Publishing. https://doi.org/10.1007/978-3-319-44558-8_ 3

Kapoor, E., Collazo-Clavell, M. L., \& Faubion, S. S. (2017). Weight gain in women at midlife: A concise review of the pathophysiology and strategies for management. Mayo Clinic Proceedings, 92(10), 15521558.

Kavaliauskas, M., Steer, T. P., \& Babraj, J. A. (2017) Cardiorespiratory fitness and aerobic performance adaptations to a 4-week sprint interval training in young healthy untrained females. Sport Sciences for Health, 13(1), 1723. https://doi.org/10.1007/s11332-016-0313-x.

Karstoft, K., Wallis, G. A., Pedersen, B. K., \& Solomon, T. P. J. (2016). The effects of interval- vs. continuous exercise on excess post-exercise oxygen consumption and substrate oxidation rates in subjects with type 2 diabetes. Metabolism, 65(9), 1316-1325.

Karvonen-Gutierrez, C., \& Kim, C. (2016). Association of mid-life changes in body size, body composition and obesity status with the menopausal transition. Healthcare, 4(3), 10.3390/healthcare4030042.

Keating, S. E., Johnson, N. A., Mielke, G. I., \& Coombes, J. S. (2017). A systematic review and meta-analysis of interval training versus 
moderate-intensity continuous training on body adiposity. Obesity Reviews, 18(8), 943-964.

Kessler, H. S., Sisson, S. B., \& Short, K. R. (2012). The potential for high-intensity interval training to reduce cardiometabolic disease risk. Sports Medicine, 42(6), 489-509. https://doi.org/10.2165/11630910000000000-00000.

Kong, Z., Fan, X., Sun, S., Song, L., Shi, Q., \& Nie, J. (2016). Comparison of highintensity interval training and moderate-to-vigorous continuous training for cardiometabolic health and exercise enjoyment in obese young women: A randomized controlled trial. PLoS ONE, 11(7), e0158589.

Kozakowski, J., Gietka-Czernel, M., Leszczyńska, D., \& Majos, A. (2017). Obesity in menopause - our negligence or an unfortunate inevitability? Menopausal Review, 2, 61-65. https://doi.org/10.5114/pm.2017.68594.

Kriel, Y., Askew, C. D., \& Solomon, C. (2018). The effect of running versus cycling high-intensity intermittent exercise on local tissue oxygenation and perceived enjoyment in 18-30-year-old sedentary men. PeerJ, 6, e5026.

Kuriyan, R. (2018) Body composition techniques. Indian Journal of Medical Research, 148(5), 648https://doi.org/10.4103/ijmr.ijmr_1777_18.

Lizcano, F., \& Guzmán, G. (2014). Estrogen deficiency and the origin of obesity during menopause. BioMed Research International, 2014, 757461.

Lovejoy, J. C., Champagne, C. M., de Jonge, L., Xie, H., \& Smith, S. R. (2008). Increased visceral fat and decreased energy expenditure during the menopausal transition. International Journal of Obesity, 32(6), 949-958. https://doi.org/10.1038/ijo.2008.25.

MacInnis, M. J., \& Gibala, M. J. (2017). Physiological adaptations to interval training and the role of exercise intensity. Journal of Physiology, 595(9), 2915-2930.

Maillard, F., Rousset, S., Pereira, B., Traore, A., de Pradel Del Amaze, P., Boirie, Y., ... Boisseau, N. (2016). High-intensity interval training reduces abdominal fat mass in postmenopausal women with type 2 diabetes. Diabetes \& Metabolism, 42(6), 433-441.

Maillard, F., Pereira, B., \& Boisseau, N. (2018). Effect of high-intensity interval training on total, abdominal and visceral fat mass: A meta-analysis. Sports Medicine, 48(2), 269-288.

Mandrup, C. M., Egelund, J., Nyberg, M., Lundberg Slingsby, M. H., Andersen, C. B., Løgstrup, S., ... Hellsten, Y. (2017). Effects of high-intensity training on cardiovascular risk factors in premenopausal and postmenopausal women. American Journal of Obstetrics and Gynecology, 216(4), 384.e1384.e11.

Mirghani, S. J., \& Yousefi, M. S. (2014). The effect of interval recovery periods during HIIT on liver enzymes and lipid profile in overweight women. Science and Sports, 30(3), 147-154.

Monteleone, P., Mascagni, G., Giannini, A., Genazzani, A. R., \& Simoncini, T. (2018). Symptoms of menopause-Global prevalence, physiology and implications. Nature Reviews. Endocrinology, 14(4), 199-215.

Mulasi, U., Kuchnia, A. J., Cole, A. J., \& Earthman, C. P. (2015). Bioimpedance at the bedside. Nutrition in Clinical Practice, 30(2), 180-193. https://doi. org/10.1177/0884533614568155.

Naves, J. P. A., Viana, R. B., Rebelo, A. C. S., de Lira, C. A. B., Pimentel, G. D., Lobo, P. C. B., ...Gentil, P. (2018). Effects of high-intensity interval training vs. sprint interval training on anthropometric measures and cardiorespiratory fitness in healthy young women. Frontiers in Physiology, 9, 1738.

Nie, J., Zhang, H., He, Y., et... al. (2019). The impact of high-intensity interval training on the cTnT response to acute exercise in sedentary obese young women. Scandinavian Journal of Medicine Science in Sports, 29(2), 160-170. https://doi.org/10.1111/sms.13344

Nieman, D. C., Nehlsen-Cannarella, S. L., Fagoaga, O. R., Henson, D. A., Utter, A., Davis, J. M., ... Butterworth, D. E. (1998). Effects of mode and carbohydrate on the granulocyte and monocyte response to intensive, prolonged exercise. Journal of Applied Physiology, 84(4), 1252-1259. https://doi.org/10.1152/jappl.1998.84.4.1252.

Palmer, B. F., \& Clegg, D. J. (2015). The sexual dimorphism of obesity. Molecular and Cellular Endocrinology, 402, 113-119.
Panissa, V. L. G., Julio, U. F., França, V., Lira, F. S., Hofmann, P., Takito, M. Y., \& Franchini, E. (2016). Sex-related differences in self-paced all out high-intensity intermittent cycling: Mechanical and physiological responses. Journal of Sports Science \& Medicine, 15(2), 372-378.

Pedersen, S. B., Kristensen, K., Hermann, P. A., Katzenellenbogen, J. A., \& Richelsen, B. (2004). Estrogen controls lipolysis by up-regulating $\alpha 2 \mathrm{~A}$-adrenergic receptors directly in human adipose tissue through the estrogen receptor $\alpha$. Implications for the female fat distribution. The Journal of Clinical Endocrinology \& Metabolism, 89(4), 1869-1878. https: //doi.org/10.1210/jc.2003-031327.

Poehlman, E. T. (2005). Menopause, energy expenditure, and body composition. Acta obstetricia et gynecologica Scandinavica. 84(11), 1131. https://doi.org/10.1111/j.0001-6349.2005.00904e.x

Prakash, M. D., Stojanovska, L., Nurgali, K., \& Apostolopoulos, V. (2017). Exercise in menopausal women. In A. C. Hackney (Ed.), Sex Hormones, Exercise and Women: Scientific and Clinical Aspects (pp. 285-307).

Rettberg, J. R., Yao, J., \& Brinton, R. D. (2014). Estrogen: A master regulator of bioenergetic systems in the brain and body. Frontiers in Neuroendocrinology, 35(1), 8-30. https://doi.org/10.1016/j.yfrne.2013.08.001.

Roy, M., Williams, S. M., Brown, R. C., Meredith-Jones, K. A., Osborne, H., Jospe, M., \& Taylor, R. W. (2018). High-intensity interval training in the real world: Outcomes from a 12-month intervention in overweight adults. Medicine and Science in Sports and Exercise, 50(9), 1818-1826.

Sandstad, J., Stensvold, D., Hoff, M., Nes, B. M., Arbo, I., \& Bye, A. (2015). The effects of high intensity interval training in women with rheumatic disease: A pilot study. European Journal of Applied Physiology, 115(10), 2081-2089.

Sawyer, B. J., Tucker, W. J., Bhammar, D. M., Ryder, J. R., Sweazea, K. L., \& Gaesser, G. A. (2016). Effects of high-intensity interval training and moderate-intensity continuous training on endothelial function and cardiometabolic risk markers in obese adults. Journal of Applied Physiology, 121(1), 279-288.

Scott, C. B., Littlefield, N. D., Chason, J. D., Bunker, MichaelP, \& Asselin, E. M. (2006). Differences in oxygen uptake but equivalent energy expenditure between a brief bout of cycling and running Nutrition \& Metabolism, 3(1), 1. https://doi.org/10.1186/1743-7075-3-1.

Shuster, A., Patlas, M., Pinthus, J. H., \& Mourtzakis, M. (2012). The clinical importance of visceral adiposity: A critical review of methods for visceral adipose tissue analysis. British Journal of Radiology, 85(1009), 1-10.

Sijie, T., Hainai, Y., Fengying, Y., \& Jianxiong, W. (2012). High intensity interval exercise training in overweight young women. Journal of Sports Medicine and Physical Fitness, 52(3), 255-262.

Smith-Ryan, A. E., Trexler, E. T., Wingfield, H. L., \& Blue, M. N. M. (2016). Effects of high-intensity interval training on cardiometabolic risk factors in overweight/obese women. Journal of Sports Sciences, 34(21), 20382046.

Stavrinou, P., Bogdanis, G., Giannaki, C., Terzis, G., \& Hadjicharalambous, M. (2018). High-intensity interval training frequency: Cardiometabolic effects and quality of life. International Journal of Sports Medicine, 39(03), 210-217. https://doi.org/10.1055/s-0043-125074.

Stavrinou, P. S., Bogdanis, G. C., Giannaki, C. D., Terzis, G., \& Hadjicharalambous, M. (2019). Effects of high-intensity interval training frequency on perceptual responses and future physical activity participation. Applied Physiology, Nutrition, and Metabolism, 44(9), 952957. https://doi.org/10.1139/apnm-2018-0707.

Steckling, F. M., Farinha, J. B., Santos, D. L. D., Bresciani, G., Mortari, J. A., Stefanello, S. T., ... Soares, F. A. A. (2016). High intensity interval training reduces the levels of serum inflammatory cytokine on women with metabolic syndrome. Experimental and Clinical Endocrinology \& Diabetes, 124(10), 597-601.

Steckling, F. M., Farinha, J. B., da Figueiredo, F. C., Santos, D. L. D., Bresciani, G., Kretzmann, N. A., ... Soares, F. A. A. (2019). High-intensity interval training improves inflammatory and adipokine profiles in postmenopausal women with metabolic syndrome. Archives of Physiology and Biochemistry, 125(1), 85-91. 
Sun, S., Zhang, H., Kong, Z., Shi, Q., Tong, T. K., \& Nie, J. (2018). Twelve weeks of low volume sprint interval training improves cardio-metabolic health outcomes in overweight females. Journal of Sports Sciences, 37(11), 12571264.

Taylor, J., Keating, S. E., Leveritt, M. D., Holland, D. J., Gomersall, S. R., \& Coombes, J. S. (2017). Study protocol for the FITR Heart Study: Feasibility, safety, adherence, and efficacy of high intensity interval training in a hospital-initiated rehabilitation program for coronary heart disease. Contemporary Clinical Trials Communications, 8, 181-191. https: //doi.org/10.1016/j.conctc.2017.10.002.

Tong, T. K., Zhang, H., Shi, H., Liu, Y., Ai, J., Nie, J., \& Kong, Z. (2018). Comparing time efficiency of sprint vs. High-intensity interval training in reducing abdominal visceral fat in obese young women: A randomized, controlled trial. Frontiers in Physiology, 9, 1048.

Trapp, E. G., Chisholm, D. J., Freund, J., \& Boutcher, S. H. (2008). The effects of high-intensity intermittent exercise training on fat loss and fasting insulin levels of young women. International Journal of Obesity, 32(4), 684-691.

Türk, Y., Theel, W., Kasteleyn, M. J., Franssen, F. M. E., Hiemstra, P. S., Rudolphus, A., ... Braunstahl, G. J. (2017). High intensity training in obesity: A meta-analysis. Obesity Science \& Practice, 3(3), 258-271.

van Gemert, W. A., Peeters, P. H., May, A. M., Doornbos, A. J. H., Elias, S. G., van der Palen, J., ...Monninkhof, E. M. (2019). Effect of diet with or without exercise on abdominal fat in postmenopausal women-A randomised trial. BMC Public Health, 19(1), 174.

Verheggen, R. J. H. M., Maessen, M. F. H., Green, D. J., Hermus, A. R. M. M., Hopman, M. T. E., \& Thijssen, D. H. T. (2016). A systematic review and meta-analysis on the effects of exercise training versus hypocaloric diet: Distinct effects on body weight and visceral adipose tissue. Obesity Reviews, 17(8), 664-690.

Vieira-Potter, V. J., Padilla, J., Park, Y.-M., Welly, R. J., Scroggins, R. J., Britton, S. L., ... Thyfault, J. P. (2015). Female rats selectively bred for high intrinsic aerobic fitness are protected from ovariectomy- associated metabolic dysfunction. American Journal of PhysiologyRegulatory, Integrative and Comparative Physiology, 308(6), R530-R542. https://doi.org/10.1152/ajpregu.00401.2014

Wajchenberg, B. L. (2000). Subcutaneous and visceral adipose tissue: Their relation to the metabolic syndrome. Endocrine Reviews, 21(6), 697-738. https://doi.org/10.1210/edrv.21.6.0415.

Weston, K. S., Wisløff, U., \& Coombes, J. S. (2014). High-intensity interval training in patients with lifestyle-induced cardiometabolic disease: A systematic review and meta-analysis. British Journal of Sports Medicine, 48(16), 1227-1234.

Wewege, M., van den Berg, R., Ward, R. E., \& Keech, A. (2017). The effects of high-intensity interval training vs. moderate-intensity continuous training on body composition in overweight and obese adults: A systematic review and meta-analysis. Obesity Reviews, 18(6), 635646.

Zhang, H. K., Tong, T., Qiu, W., Wang, J., Nie, J., \& He, Y. (2015). Effect of high-intensity interval training on abdominal fat reduction in overweight chinese women: A randomized controlled trial. Kinesiology, 47(1), 57-66.

Zhang, H., Tong, T. K., Qiu, W., Zhang, X., Zhou, S., Liu, Y., \& He, Y. (2017). Comparable effects of high-intensity interval training and prolonged continuous exercise training on abdominal visceral fat reduction in obese young women. Journal of Diabetes Research, 2017, 5071740.

How to cite this article: Dupuit M, Maillard F, Pereira B, Marquezi ML, Lancha AH, Boisseau N. Effect of high intensity interval training on body composition in women before and after menopause: a meta-analysis. Experimental Physiology. 2020;1-21. https://doi.org/10.1113/EP088654 